\title{
CONGRUÊNCIA ENTRE POLÍTICAS SOCIAIS, DE SEGURANÇA PÚBLICA, E OPINIÃO DOS CIDADÃOS NO BRASIL
}

\author{
Yan de Souza Carreirão* (https://orcid.org/0000-0002-3964-0350) \\ Peterson Roberto da Silva** (https://orcid.org/0000-0001-6206-2002) \\ Maria Teresa de Bastiani ** * (https://orcid.org/0000-0002-7617-7588)
}

\begin{abstract}
Este trabalho se insere no campo de estudos empíricos sobre representação política, seguindo a perspectiva da análise da "congruência política", uma área de estudos importante na literatura internacional, mas ainda muito pouco desenvolvida no Brasil. Analisa, de um lado, a evolução das opiniões dos cidadãos brasileiros a respeito de temas na área social (saúde, educação e trabalho) e na área de segurança pública e, de outro, verifica em que medida há congruência entre essas opiniões e a legislação em vigor sobre esses temas. Embora não seja possível generalizar, as conclusões do trabalho mostram que a opinião majoritária dos cidadãos brasileiros tem se mostrado mais "progressista" em relação às políticas de educação e de trabalho e mais "conservadora" em relação ao tema do aborto e, principalmente, em relação à área de segurança pública. Quanto à legislação, a análise revela um elevado grau de "inércia legislativa", pois, tanto nos casos de congruência quanto nos de incongruência, predominam situações em que não há mudança da legislação.

Palavras-chave: Comportamento político. Representação Política. Opinião pública. Congruência Política. Políticas públicas.
\end{abstract}

\section{INTRODUÇÃO}

Este artigo estuda o tema da representação política, mais precisamente a partir do enfoque da "congruência política", ou seja, analisa se há concordância (congruência) entre, de um lado, a opinião majoritária dos cidadãos brasileiros em relação a diferentes temas políticos e, de outro, as políticas efetivamente aprovadas por seus representantes em relação a esses temas.

Embora a literatura sobre congruência política (policy congruence) seja pouco conhecida no Brasil, uma ampla produção se desenvolveu nos últimos 50 anos, especialmente nos EUA e na Europa. O trabalho que mais influenciou o desenvolvimento inicial desse campo de estudos é o de Miller e Stokes (1963). Em

* Universidade Federal de Santa Catarina, Centro de Filosofia e Ciências Humanas, Departamento de Ciências Sociais. Campus Universitário Reitor João David Ferreira Lima, s/ $\mathrm{n}^{\circ}$. Trindade. Cep: 88040-900. Florianópolis - Santa Catarina-Brasil. yancarreirao@uol.com.br

* * Universidade Federal de Santa Catarina.

Campus Universitário Reitor João David Ferreira Lima, s/ $\mathrm{n}^{\circ}$. Trindade. Cep: 88040-900. Florianópolis - Santa Catarina-Brasil. peterson.235@gmail.com

*** Universidade Federal de Santa Catarina.

Campus Universitário Reitor João David Ferreira Lima, s/ $\mathrm{n}^{\mathrm{o}}$. Trindade. Cep: 88040-900. Florianópolis - Santa Catarina-Brasil.mteresa.debastiani@gmail.com sua pesquisa empírica, o trabalho desses autores tomou como preocupação central a congruência entre representantes (individualmente) e seus eleitorados (constituencies), definidos geograficamente a partir dos distritos eleitorais. Weissberg (1978, p. 535) critica a concepção de representação enfatizada no trabalho empírico de Miller e Stokes (e dos estudos que o seguiram), que chama de "representação diádica", propondo a análise da representação a partir do que chama de "representação coletiva". $\mathrm{Na}$ perspectiva diádica, a comparação se faz entre um representante e um eleitorado. Apesar de sua relevância, mais importante do que ver se cada membro do Congresso representa seu distrito, seria verificar se o Congresso como um todo representa o conjunto do povo americano, segundo Weissberg.

Segundo Dalton (2008, p. 226), alguns estudos seguiram ainda o artigo de Miller e Stokes (1963), mas a tendência foi a de uma diminuição gradual do uso de um modelo baseado em legisladores individuais e uma ênfase em estudos que seguiram o modelo proposto por Weissberg. Um desenvolvimento importante, nesses estudos, se dá com a incorporação de 
uma perspectiva dinâmica de representação. O artigo de Page e Shapiro (1983), por exemplo, analisava todos os casos em que havia pelo menos dois surveys com opiniões dos cidadãos sobre um mesmo tema e examinava não só as correlações entre mudanças na opinião pública e mudanças nas políticas governamentais nos EUA, mas, em caso de congruência, verificava se os indícios indicavam que a opinião influenciava a política, ou o inverso. Vários trabalhos posteriores tentaram melhorar o desenho da pesquisa, analisando não apenas dois surveys, mas séries históricas mais amplas de opiniões dos cidadãos em relação às questões políticas (verificando, ao longo do período de estudo, todas as mudanças nas políticas correspondentes a essas questões). Outro desenvolvimento importante ocorre com a realização de estudos comparados envolvendo vários países (Golder; Stramski, 2010, Rohrschneider; Whitefield, 2012), ou mesmo uma produção que analisa dados comparados de vários países em uma perspectiva "dinâmica" (Budge et al., 2012; Dalton; Farrell; Mcallister, 2011; Soroka; Wlezien, 2010).

Na revisão da produção brasileira feita até aqui, conseguimos identificar apenas poucos trabalhos que podem ser enquadrados como estudos de congruência política no Brasil (Ames; Pereira; Rennó, 2011; Boas; Smith, 2017; N. Carreirão; Melo, 2014; Pederiva; Rennó, 2015). ${ }^{1}$ Há, portanto, uma séria escassez de análises empíricas no país no que se refere aos estudos de congruência. Este trabalho pretende contribuir para suprir parcialmente essa escassez.

Este artigo é um resultado parcial de uma pesquisa mais ampla que busca analisar a congruência política entre as preferências dos cidadãos brasileiros em relação a todos os temas de políticas públicas possíveis - captadas a partir das pesquisas de opinião disponíveis no país - e as políticas efetivamente aprovadas pelo Congresso no período pós-Constituição de 1988.

${ }^{1}$ Uma análise mais detalhada tanto da ampla produção internacional quanto da escassa produção nacional pode ser encontrada em (é Carreirão (2015).
Na próxima seção, discutimos os conceitos de representação política e responsividade, indicando sua relação com a análise de congruência política. Depois, apresentamos os objetivos, as hipóteses, os dados e a metodologia do trabalho. Na seção seguinte, analisamos os dados e, então, apresentamos algumas considerações finais.

\section{REPRESENTAÇÃO, RESPONSIVI- DADE, CONGRUÊNCIA}

Pitkin (1967), após revisar uma ampla literatura, mostra que o conceito de representação assumiu significados os mais variados. Ao final de seu livro, formula sua própria definição: "representar [...] significa agir no interesse dos representados de uma maneira responsiva a eles" (Pitkin, 1967, p. 209). Sobre a ideia de responsividade, afirma que o representante deve agir de forma que não haja conflito com o representado sobre o que deve ser feito e, caso isso ocorra, deve buscar uma explicação para isso. Ele não deve estar em conflito persistentemente com as opiniões de seus representados sem boas razões, em termos dos interesses desses últimos, sem uma boa explicação para o desacordo (idem p. 209-210). De forma semelhante, para Manin, Przeworski e Stokes (1999, p. 2): representar é "agir no melhor interesse do público”. E um governo é responsivo se adota políticas que os cidadãos sinalizam como sendo suas preferidas. O conceito de responsividade (responsiveness), então, supõe que os representantes tomem decisões levando em consideração a emissão prévia de mensagens pelos cidadãos. ${ }^{2}$ Mas as relações entre responsividade e (boa) representação não são simples. Um governo pode ser representativo mesmo que não seja responsivo aos desejos expressos do

${ }^{2}$ Esses sinais podem incluir pesquisas de opinião, várias formas de ação direta (incluindo manifestacões, campanhas etc.) e, durante as eleições, votos em determinadas plataformas. "Mandatos" constituem um tipo particular de sinais que são emitidos nas eleições: eles constituem uma escolha entre propostas (plataformas, mesmo que vagas) oferecidas por equipes de políticos (Manin; Przeworski; Stokes1999, p. 9). 
público e, inversamente, pode ser não representativo mesmo que siga as preferências sinalizadas pelo público. Se as "instruções" dos eleitores são baseadas em pressupostos errados, então o governo pode traí-los de boa-fé, para alcançar seus melhores interesses (Manin; Przeworski; Stokes, 1999, p.10-11). ${ }^{3}$ Não haveria, portanto, uma relação necessária entre ser responsivo e ser um bom representante.

Na literatura sobre congruência política, porém, a ideia de congruência tende a se aproximar mais da noção de responsividade; não se toma como base a ideia de interesse (dos cidadãos) e sim noções como as de preferências, desejos ou opiniões. A eventual tensão entre preferências (ou desejos ou opiniões) e interesses - que transparece a partir do conceito de representação de Manin, Przeworski e Stokes (1999) - virtualmente desaparece nessa literatura sobre congruência política, dando lugar a uma investigação mais direta sobre a correspondência entre a opinião dos eleitores e as opiniões dos representantes (ou as políticas que eles aprovam). É a esse último tipo de investigação que os estudos de congruência política se dedicam. Cabe ainda mencionar que a existência de congruência (entre políticas públicas e opiniões dos eleitores) não necessariamente pressupõe uma relação de causalidade: a congruência pode existir porque os representantes são responsivos, ou seja, seguem as preferências dos cidadãos. Mas, a congruência pode ocorrer também por coincidência de opiniões entre eleitores e representantes, ou por persuasão desses últimos, de forma a que os eleitores passam a assumir as preferências políticas de seus líderes ou representantes. Alguns estudos visam não só a verificar a existência (ou não) de congruência entre a opinião dos eleitores e a ação dos representantes, mas, caso haja congruência, analisar a sequência temporal entre o momento em que a opinião dos eleitores sobre determinado tema é conhecida e o momento em que os represen-

${ }^{3} \mathrm{Na}$ perspectiva de Pitkin, nesse caso, os representantes precisariam explicar a seus representados por que julgam que seguir seus desejos não seria o melhor para alcançar seus interesses. tantes aprovam mudanças numa lei sobre esse tema. Tentaremos, dentro dos limites impostos pelos dados, seguir esse caminho. ${ }^{4}$

Um texto influente é o de Page e Shapiro (1983), que examina as correlações entre mudanças na opinião pública e mudanças nas políticas governamentais nos EUA, entre 1935 e 1979. Os autores buscam verificar se as mudanças nas políticas se dão na mesma direção ou na direção contrária às da opinião pública. ${ }^{5} \mathrm{E}$ verificam os momentos em que essas mudanças se dão (se as opiniões mudam antes ou depois das políticas), para sugerir possíveis relações de causalidade. Nas conclusões, afirmam que a substancial congruência entre opinião e políticas (especialmente quando as mudanças de opinião são grandes e estáveis e os issues são salientes ${ }^{6}$ ) em conjunto com as evidências de que a opinião muda antes das políticas indicam que mudanças de opinião são causas importantes de mudanças em políticas. Mas advertem que há diversas razões para não ser conclusivo em postular que a responsividade é pervasiva na política americana e que o público obtém dos políticos o que desejam. Por fim, advertem que, mesmo que as políticas respondam a mudanças de opinião, é preciso cautela ao afirmar que isso corresponde a um mecanismo democrático, já que a opinião pode ser afetada por fatores não totalmente compatíveis com conceitos normativos de democracia: "se, por exemplo, políticos ou grupos de interesse conseguem manipular a opinião pública através de mentiras ou fraudes

${ }^{4}$ Uma discussão mais aprofundada do referencial teórico pode ser encontrada em (Carreirão, 2015).

${ }^{5}$ Os pesquisadores reuniram mais de três mil questões, sendo que 609 delas foram repetidas duas ou mais vezes entre 1935-79. Só essas foram inicialmente incluídas na análise, pois só quando há duas ou mais questões similares ao longo do tempo é possível verificar se houve ou não mudança na opinião dos eleitores. Ao cabo, localizaram 357 pontos de significativa mudança na opinião pública sobre políticas nos Estados Unidos durante o período (Page; Shapiro, 1983, p. 177)

6 Os autores usam dois critérios para verificar a saliência de um issue: o primeiro utiliza a proporção de respostas "não sei" ou "não respondeu". Uma proporcão baixa seria um indicativo de maior interesse da opinião pública no assunto. O segundo é a frequência com que aparece uma pergunta nos surveys, partindo do pressuposto de que os institutos de pesquisa estão atentos aos debates da sociedade e fazem perguntas sobre o que julgam ser mais importante para os cidadãos. 
e as políticas em seguida respondem à opinião manipulada, nós devemos hesitar em celebrar o resultado como democrático." (Page; Shapiro, 1983, p. 189, tradução nossa).

\section{Objetivos, hipóteses, dados e metodologia}

O objetivo central da análise é verificar em que medida há congruência entre a legislação aprovada (ou em vigor) e a opinião majoritária da população em relação aos temas cobertos por essa legislação, tentando discernir diferentes possibilidades de perceber congruência ou incongruência, a partir de uma tipologia que será apresentada mais à frente. Analisaremos, também, se há padrões diferentes para as quatro áreas temáticas aqui analisadas (segurança pública, saúde, educação e trabalho). Será possível também avaliar a evolução das preferências dos eleitores brasileiros em relação aos temas para os quais temos dados.

Serão, além disso, testadas duas hipóteses: - H1: quanto maior a diferença entre a porcentagem da população que sustenta a opinião majoritária e a porcentagem que adere à opinião minoritária em relação a um tema, maior a chance de haver congruência.

A suposição é a de que, em temas em relação

aos quais haja uma ampla maioria, o custo para os representantes aprovarem ou manterem uma legislação contrária a essa maioria é maior do que num caso em que a população esteja razoavelmente dividida.

- H2: as chances de ocorrer congruência são maiores em temas mais salientes (ou seja, teoricamente, de maior importância para a população).

A suposição é a de que, em temas que são de maior importância, a população fica mais atenta às decisões tomadas pelos legisladores, e eles, antecipando esse comportamento dos eleitores, tendem a ser mais responsivos. Como indicadores da saliência dos temas, seguiremos Page e Shapiro (1983), que levam em consideração, de um lado, o número de vezes em que um tema aparece nas pesquisas ao longo do tempo e, de outro, a porcentagem de respostas não sabe ou não respondeu (NS, NR). As suposições são: i) a de que acadêmicos e institutos de pesquisa tendem a ter uma percepção dos temas de maior interesse do público, incluindo questões sobre esses temas mais frequentemente em seus surveys; ii) a de que, em temas de maior importância para os cidadãos, eles formam uma opinião mais facilmente do que em temas para os quais dão menos importância.

Para esta pesquisa, foi construído um Banco de Opiniões dos Eleitores sobre Políticas Públicas, que se iniciou com a busca de dados existentes em centenas de pesquisas de opinião disponíveis no Centro de Estudos de Opinião Pública (CESOP - Unicamp), World Values Survey (WVS), LAPOP (Barômetro das Américas), Latinobarômetro; sites dos institutos Datafolha e Ibope; site da Confederação Nacional de Transportes (pesquisas CNT-Sensus). Em cada pesquisa (relatório ou base de dados), foram selecionadas as questões que se enquadram no tipo adequado para nossa pesquisa. ${ }^{7}$

Embora se trate de variadas fontes e de diferentes metodologias de amostragem e elaboração de questionários, acreditamos que, num contexto como o nosso, em que a quantidade de pesquisas de opinião é reduzida, é melhor incluir o máximo de pesquisas, mesmo com os eventuais problemas derivados dessa diversidade. Cabe mencionar que, até num contexto como o norte-americano, em que há grande número de surveys oriundos de pesquisas acadêmicas e de institutos conhecidos, Monroe (1998) busca dados também de uma grande variedade de fontes, incluindo institutos menos conhecidos. ${ }^{8}$

7 Só questões que impliquem escolhas para os entrevistados, semelhantes às que os representantes têm de fazer no processo decisório legislativo. Como assinala Monroe (1998, p. 10): "to be selected, a survey question had to deal with a question of potential federal policy, specific enough that it might be possible to determine whether or not federal policy complied with the terms of the question."

8 "Most of the survey items came from well-known sources such as Gallup, the Harris Poll, surveys conducted for the several print and network alliances, and the annual sur- 
Nosso estudo toma como referência, do ponto de vista da metodologia, principalmente os estudos de Monroe $(1979,1998)$ e Page e Shapiro (1983), investigando em que medida há congruência entre as preferências dos eleitores brasileiros e as políticas públicas (em vigor ou modificadas depois pelo Congresso Nacional) em relação a temas relativos à área de segurança pública e a temas sociais (saúde, educação, trabalho e assistência social). Antes de indicar nossos procedimentos metodológicos, vamos apresentar brevemente aqueles trabalhos. Monroe (1998) investiga se as decisões a respeito de políticas tomadas pelo governo norte-americano foram consistentes com a preferência do povo americano; seu recorte temporal foi o período de 1980 a 1993, e ele confrontou os dados obtidos em sua pesquisa com dados de uma pesquisa que havia feito, relativa a duas décadas anteriores (Monroe, 1979). O método escolhido pelo autor toma surveys feitos em um determinado ponto no tempo e compara a distribuição da opinião pública em relação às políticas. Sua principal conclusão, resumidamente, é que, no período de 19601979, a consistência entre preferências dos eleitores e políticas era de $63 \%$; no entanto, no período de 1980-993, cai para 55\% (Monroe, 1998, p. 12). Além disso, mostra que, nos dois períodos, havia maior consistência entre opinião pública e políticas públicas em assuntos de maior saliência (ou seja, em temas potencialmente mais importantes para os eleitores).

Cabe ressaltar que, em nosso estudo, valem algumas das ressalvas metodológicas presentes no estudo de Monroe quanto à impossibilidade de postular relações de causalidade entre a expressão da opinião por parte do público e o processo legislativo.

The method used here, based on analysis of public opinion measured at one point in time cannot, fundamentally, prove that public opinion caused or even influenced a policy outcome. The most basic problem

veys of the National Opinion Research Center, though results from a number of less prominent agencies were also included" (Monroe, 1998, p.10, ênfase nossa). is the lack of a guarantee of temporal priority as some surveys were conducted after a policy decision was made. (...) More difficult to assess is the causality criterion of nonspuriousness; neither this method nor the alternatives discussed earlier can completely rule out the possibility that some other variables may have caused any apparent relationship between opinions and policies. A number of controls will be used to rule out some possible factors. The possibility still remains that other forces, for example, elite control of the news media, might have conceivably manipulated both public preferences and government decisions. Page and Shapiro (1989) suggest that this may have occurred in some instances. On the other hand, if there is a lack of consistency (i.e., covariation) between mass public opinion and the actions of government, one could reasonably conclude that popular influence on government decisions was lacking (Monroe, 1998, p. 12).

\section{Análise dos dados}

Os dados serão apresentados a partir de uma tipologia criada para enquadrar todos os "casos". Cada tema (ou subtema) específico será considerado um "caso", se não tiver ocorrido nenhuma mudança na legislação ou na opinião majoritária do eleitorado em relação ao tema, ao longo do período analisado (19892017). Caso tenha havido mudança na legislação ao longo desse período, podemos ter outro caso (um antes e outro depois da mudança); da mesma forma, se tivermos uma (ou mais) mudança(s) na opinião majoritária em relação a um tema, teremos dois (ou mais) casos. ${ }^{9}$

As situações em que a opinião majoritária mudou num período menor do que quatro anos foram desconsiderados na análise de congruência, na suposição de que esse seria um tempo mínimo entre a expressão da opinião e uma eventual resposta por parte do Con-

${ }^{9}$ Seguimos, aqui, o procedimento utilizado por Monroe (1998, p. 10-11): "More than one use of questions on the same policy alternatives were used in only two circumstances. First, if the net distribution shifted from a plurality on one side of the issue to the other, both distributions were used and the issue then created two different cases. (...) Second, if a substantial policy changes intervened, then the issue could be used more than once". 
gresso. ${ }^{10}$ Assim, em relação ao tema da pena de morte, por exemplo, embora tenha havido muitas variações na opinião majoritária sobre o tema, ficamos apenas com dois casos: um primeiro, entre 1991 e 2001, em que quatro pesquisas disponíveis apontavam uma maioria a favor da pena de morte (caso de incongruência, portanto), e um segundo, entre 2008 e 2017, em que nas 13 pesquisas disponíveis a maioria se mostrou contra a pena de morte (caso de congruência). No período entre 2001 e 2008, 21 pesquisas foram feitas, com várias mudanças na opinião majoritária (em geral, com diferenças relativamente pequenas entre a maioria e a minoria em cada momento), sem que uma dessas opiniões perdurasse como majoritária por mais de 24 meses sem ser sobrepujada pela opinião oposta. Por isso, não classificamos os resultados relativos a esse período. ${ }^{11}$

A princípio, classificamos todos os "casos”, definidos como foi descrito acima, em seis diferentes "tipos": três tipos de congruência e três de incongruência. Congruência: 1) casos em que uma mudança de legislação ocorre num momento posterior a uma pesquisa que revela uma maioria favorável à mudança; 2) casos em que não houve mudança na legislação, seguindo a opinião majoritária dos cidadãos (contrária à mudança); 3) casos em que uma pesquisa Э. é aplicada após uma mudança da legislação, กิ mostrando que a maioria do público a apro送 vou. Incongruência: 4) casos em que não houve mudança da legislação, quando havia apoio manifesto a essa mudança; 5) casos em que o Congresso aprova uma legislação em relação à qual a maioria dos cidadãos é contra; 6) casos em que, após uma mudança da legislação,

${ }^{10}$ Isso ocorreu apenas em relação a dois temas (aos quais faremos menção mais à frente): aborto em caso de estupro e pena de morte.

${ }^{11} \mathrm{O}$ mesmo tipo de situação ocorreu em relação ao tema das cotas raciais para ingresso nas universidades. Em సี uma pesquisa realizada em novembro de 2002, a maioria se colocou contra (o que era congruente com a legislação à época). Já em setembro do ano seguinte, uma pesquisa

mostrava uma maioria favorável à medida. Os dez meses

transcorridos entre a $1^{\mathrm{a}}$ e a $2^{\mathrm{a}}$ pesquisas não foram levados em consideração como constituindo um "caso" de congruência, pelo pequeno intervalo de tempo em que houve mudança na posição majoritária. uma pesquisa mostra que a maioria do público a reprovou. Embora esse último tipo tenha sido definido seguindo o mesmo critério usado para definir o tipo 3, não encontramos nenhum caso que se enquadrasse nesse tipo (6), razão pela qual, na prática, ficamos com os primeiros cinco tipos. Os pouquíssimos casos em que ocorreu "empate técnico" (dentro da margem de erro da amostra) entre as posições majoritária e minoritária da população não foram classificados na tipologia, ficando fora da análise.

Mudanças na legislação em consonância com a opinião do público, mas operadas mais de quatro anos após a medição da opinião, não foram consideradas como parte desse tipo de caso. Seguindo Page e Shapiro (1983, p. 177), consideramos esse como o tempo máximo para uma eventual "resposta" do Legislativo a uma "sinalização" do público. Situações desse tipo foram enquadradas como casos do "tipo 4", de incongruência entre a opinião do público e a legislação. É o caso, por exemplo, do tema das cotas raciais para empregos públicos, em que pesquisas realizadas em 2002 e 2008 mostravam uma maioria favorável à medida, que, entretanto, só foi aprovada em 2014. A aprovação da medida se deu tendo passado já 139 meses após a primeira daquelas pesquisas. Por isso, julgamos mais adequado tratar esse caso como de incongruência (durante o período entre 2002 e 2014) do que como um caso do tipo 1 , que é o que se aproximaria de um tipo ideal de "responsividade" dos representantes às demandas dos representados.

Na realidade, não há um limite claro entre as situações dos tipos 2 e 3. Apenas resolvemos separar as duas situações analiticamente, para dar ênfase, no tipo 3, à aprovação da população em relação a uma mudança relativamente recente da legislação. Mas, passado algum tempo dessa aprovação, a manifestação do público talvez deva ser interpretada mais como expressão de desejo de que a lei não mude (tipo 2), do que como uma aprovação de uma lei recente. Caso a pesquisa seja feita mais de dois anos depois da aprovação da lei, consideramos 
que a situação corresponde à do tipo 2. O mesmo critério foi adotado para diferenciar os tipos 5 e 6. Embora seja um critério arbitrário, isso não afetará nossas conclusões de forma significativa, já que os casos desses dois tipos representam uma manifestação de apoio a uma legislação em vigor (seja recente, seja antiga). Apenas nos parece que, do ponto de vista causal, fica mais difícil, nos casos de tipo 3, atribuir a congruência a uma decisão do Congresso em resposta a uma manifestação de apoio da população à manutenção da lei em vigor.

Em cada Tabela (para cada tipo de caso), indicamos a forma como o tempo - entre uma medida de opinião e a aprovação (ou não) de uma política - será considerado (e calculado), de acordo com o interesse da análise. Visando a testar o item H1, apresentamos também o “Diferencial Médio” (DM), que é uma média - para a(s) pesquisa(s) relativa(s) a cada caso - da diferença entre a posição majoritária e a minoritária. De forma a poder testar H2, apresentamos o número das pesquisas que contêm perguntas relativas a cada caso e indicamos o percentual (médio) de respostas NS ou NR. Após a apresentação das tabelas para cada

A Tabela 1 a seguir, mostra que, em apenas três casos, a congruência ocorre por uma mudança na legislação em momento posterior a uma pesquisa que revelava uma maioria dos cidadãos favorável a essa mudança.

A exigência de rotulação de produtos transgênicos foi aprovada em março de 2005 (Lei de Biossegurança), em conformidade com a opinião majoritária expressa em duas pesquisas de 2001 e 2002, a primeira delas realizada 44 meses antes da aprovação da lei. Um segundo caso é o da "lei antifumo" (Lei 12546/2011), aprovada 39 meses após uma pesquisa de opinião revelar um amplo apoio da população a uma forte restrição ao uso do tabaco em recintos (públicos) fechados. O terceiro caso é o do Programa Mais Médicos (PMM), embora esse seja um caso de mais difícil classificação: talvez pudesse ser entendido como um caso de aprovação pelo público após a edição da Medida Provisória que o instituiu (em julho de 2013), mas, como nosso estudo privilegia a aprovação de legislação no âmbito do Congresso, consideramos, aqui, como um caso de aprovação pelo Congresso (em outubro de 2013) de uma lei que estava de acordo com a opinião da maioria dos

Tabela 1 - Tipo 1. Congruência: casos em que uma mudança de legislação ocorre logo após uma pesquisa que revela uma maioria favorável à mudança

\begin{tabular}{l|l|c|c|c|c}
\hline \multirow{2}{*}{$\begin{array}{l}\text { Área } \\
\text { Temática }\end{array}$} & $\begin{array}{c}\text { Tema, posição majoritária, data das } \\
\text { pesquisas e da legislação }\end{array}$ & $\begin{array}{c}\text { No meses } \\
\text { entre opinião } \\
\text { e mudança na } \\
\text { legislação(1) }\end{array}$ & $\begin{array}{c}\text { Diferencial } \\
\text { médio } \\
\text { (\%) }\end{array}$ & $\begin{array}{c}\text { NS, NR } \\
\text { (\%) }\end{array}$ & $\begin{array}{c}\mathbf{N}^{\mathbf{0}} \text { de } \\
\text { pesquisas }\end{array}$ \\
\hline \multirow{5}{*}{ Saúde } & $\begin{array}{l}\text { Transgênicos - rotulação (maioria a } \\
\text { favor, julho de 2001 -2002; Lei de } \\
\text { Biossegurança aprovada em março } \\
\text { de 2005). }\end{array}$ & 44 & 88,5 & 5,5 & 2 \\
\cline { 2 - 6 } & $\begin{array}{l}\text { Programa Mais Médicos (PMM) } \\
\text { (maioria a favor, agosto, setembro e } \\
\text { novembro de2013; abril de 2014; lei } \\
\text { aprovada em outubro de 2013)(2) }\end{array}$ & 2 & 8,5 & 4,5 & 6 \\
\cline { 2 - 6 } & $\begin{array}{l}\text { Lei antifumo (maioria a favor, } \\
\text { setembro de 2008; Lei 12.546 } \\
\text { aprovada em dezembro de 2011). }\end{array}$ & 39 & 68,0 & 4,0 & 1 \\
\hline
\end{tabular}

Fonte: Banco de Opiniões dos Eleitores sobre Políticas Públicas (Necip, UFSC). Elaboração nossa. (1) Aqui o número de meses é calculado entre a data da pesquisa em que maioria se mostrou a favor de mudança na legislação (no caso de haver mais de uma pesquisa, consideramos a primeira e a data da aprovação dess legislação, de forma a medir o lapso de tempo entre a expressão da opinião do público e a aprovação da lei). (2) Em duas pesquisas anteriores (junho e jutho de 2013), houve "empate técnico" entre opiniões favoráveis e contrárias.

tipo, apresentamos uma análise descritiva parcial, destacando alguns dos principais casos. Ao final, tentamos uma análise mais sintética do conjunto dos dados. cidadãos (já conhecida a partir de pesquisas de agosto e setembro).

Os casos apresentados na Tabela 2 correspondem à situação em que não houve mudança na legislação ao longo do período, o que estava de acordo com a opinião expressa pela maioria dos cidadãos (contrária a essas mudanças). ${ }^{12}$

${ }^{12} \mathrm{Na}$ realidade, no que se refere à proibição do uso das drogas (item para o qual temos a opinião do público), essa legislação não modifica substantivamente a legislação anterior, de 1976. Um caso como esse talvez pudesse ser considerado mais próximo de um caso do tipo 1, já que não houve "inércia legislativa”, mas, sim, a manutenção, numa nova legislação, de um item pelo qual os cidadãos demonstraram preferência. 
Tabela 2 - Tipo 2. Congruência: casos em que não houve mudança na legislação, seguindo a opinião majoritária dos cidadãos (contrária à mudança)

\begin{tabular}{|c|c|c|c|c|c|}
\hline $\begin{array}{l}\text { Área } \\
\text { Temática }\end{array}$ & Tema, posição majoritária, data das pesquisas e da legislação & $\begin{array}{c}\mathrm{N}^{\mathrm{o}} \text { de } \\
\text { meses } \\
\text { congruente }\end{array}$ & $\begin{array}{l}\text { Diferencial } \\
\text { médio } \\
(\%)\end{array}$ & $\begin{array}{l}\text { NS, NR } \\
(\%)\end{array}$ & $\begin{array}{c}\mathrm{N}^{0} \text { de } \\
\text { pesquisas }\end{array}$ \\
\hline \multirow{3}{*}{$\begin{array}{l}\text { Segurança } \\
\text { Pública }\end{array}$} & Pena de morte (maioria contra; 2008 - 2017) & 108 & 7,0 & 5,2 & 10 \\
\hline & Privatização de presídios (maioria a favor; 2008 - 2011) & 114 & 29,7 & 9,0 & 3 \\
\hline & $\begin{array}{l}\text { Proibição ou restrição de consumo de drogas (maioria a favor; março } 1995 \text { - 2017; } \\
\text { alteração na lei em 2006; ver Nota 17) }\end{array}$ & 270 & 59,6 & 4,2 & 16 \\
\hline \multirow{12}{*}{ Saúde } & $\begin{array}{l}\text { Aborto - Quando a vida da mulher corre risco (maioria a favor; janeiro de } 1991 \text { - } \\
\text { junho, 2007) }\end{array}$ & 320 & 62,5 & 3,2 & 3 \\
\hline & $\begin{array}{l}\text { Aborto - Quando a mulher não é casada ou não quer casar com o homem que a } \\
\text { engravidou (maioria contra; janeiro de } 1991 \text { - junho de 2002) }\end{array}$ & 320 & 73,0 & 2,6 & 2 \\
\hline & $\begin{array}{l}\text { Aborto - Quando o casal ou a mulher não quer mais filhos (maioria contra; janeiro de } \\
1991 \text { - junho de 2002) }\end{array}$ & 320 & 61,1 & 4,1 & 5 \\
\hline & $\begin{array}{l}\text { Aborto - Legalização do aborto, mulher deve decidir (maioria contra; maio de } 1991 \text { - } \\
\text { setembro e 2014) }\end{array}$ & 316 & 53,3 & 7,0 & 15 \\
\hline & Aborto - Manter a lei atual (maioria a favor; setembro de 1993 - setembro de $2014^{(2)}$ & 288 & * & 6,1 & 8 \\
\hline & $\begin{array}{l}\text { Aborto - Gravidez resultante de violência sexual, estupro (maioria a favor; fevereiro de } \\
1996 \text { - janeiro de 1997) }\end{array}$ & 110 & 37,8 & 5,3 & 3 \\
\hline & Aborto em caso de microcefalia do bebê, mãe com zika (maioria contra; fevereiro de 2016) & 19 & 12,0 & 10,0 & 1 \\
\hline & Aborto - Gravidez antes dos 18 anos (maioria contra; fevereiro de 1996 - janeiro de 1997 & 259 & 60,3 & 5,5 & 3 \\
\hline & Aborto - Família em situação socioeconômica vulnerável (maioria contra; junho de 2002) & 184 & 55,5 & 2 & 1 \\
\hline & Eutanásia - Suicídio assistido (maioria contra; março de 2007) & 126 & 21,0 & 7,0 & 1 \\
\hline & $\begin{array}{l}\text { Imposto para saúde (CPMF - CSS) - recriação (maioria contra; setembro de } 2007 \text { - } \\
\text { janeiro de 2016) }\end{array}$ & 81 & 54,4 & 15,0 & 4 \\
\hline & Planejamento familiar (maioria a favor; junho de 2002 - junho de 2007; lei alterada em 1996) ${ }^{(3)}$ & 123 & 78,4 & 3,0 & 3 \\
\hline Educação & Mensalidade em universidades públicas (maioria contra; junho de 2003, 2008, 2014) & 171 & (5) & 4,0 & 3 \\
\hline \multirow{14}{*}{ Trabalho } & Cotas raciais em novelas, filmes e propagandas (maioria contra; setembro de 2008) & 108 & 11,6 & 4,7 & 1 \\
\hline & Proibição de greve (maioria contra; setembro de 1993; 1994; 1997; 2014) & 336 & 35,5 & 5,0 & 5 \\
\hline & Redução das férias para 15 dias anuais (maioria contra; fevereiro de 1996) & 259 & 20,6 & 10,4 & 1 \\
\hline & Fim do adicional de 1/3 de férias (maioria contra; fevereiro de 1996) & 259 & 22,4 & 12,8 & 1 \\
\hline & Redução de encargos relativos ao $13^{\circ}$ salário (maioria contra; fevereiro de 1996) & 259 & 45,8 & 10,3 & 1 \\
\hline & Redução ou fim da indenização em caso de demissão (maioria contra; fevereiro de 1996) & 259 & 51,0 & 12,6 & 1 \\
\hline & $\begin{array}{l}\text { Redução ou fim da contribuição obrigatória para a Previdência (maioria contra; } \\
\text { fevereiro de 1996) }\end{array}$ & 259 & 6,0 & 13,9 & 1 \\
\hline & $\begin{array}{l}\text { Transformar encargos do Seguro de Acidente de Trabalho em repasse direto aos } \\
\text { trabalhadores (maioria contra; janeiro de 2002) }\end{array}$ & 188 & 8,0 & 4,5 & 1 \\
\hline & $\begin{array}{l}\text { Transformar encargos relativos ao "Sistema S" em repasse direto aos trabalhadores } \\
\text { (maioria contra; janeiro de 2002) }\end{array}$ & 188 & 5,9 & 5,2 & 1 \\
\hline & Redução de jornada de trabalho com redução de salário (maioria contra; fevereiro de 1996) & 259 & 20,7 & 12,0 & 1 \\
\hline & Impedir empresas de usar horas extras (maioria contra; fevereiro de 1996) & 259 & 20,2 & 14,6 & 1 \\
\hline & Limitar uso de horas extras pelas empresas (maioria a favor; maio de 1996) & 259 & 2,3 & 8,9 & 1 \\
\hline & Mudança de Salário Mínimo, de nacional para regional (maioria contra; maio de 1996; 1997) & 256 & 37,0 & 7,8 & 1 \\
\hline & Proibição de trabalho para estrangeiros (maioria contra; junho e dezembro de 2002)(4) & 183 & 4,9 & 3,3 & 2 \\
\hline \multicolumn{6}{|c|}{$\begin{array}{l}\text { Fonte: Banco de Opiniões dos Eleitores sobre Políticas Públicas (Necip, UFSC). Elaboração nossa. } \\
\text { (1) Aqui foram agregadas } 15 \text { pesquisas com perguntas sobre a legalização do aborto ou sua permissão (ou legalização) "quando a mulher quiser, por qualquer } \\
\text { razão" (ou seja, sem condicionante algum). Três outras pesquisas que não foram incluídas na tabela por terem enunciado diferente reforçam as conclusões. } \\
\text { (2) O contraste era entre manter a legislação atual, ampliar o número de casos em que o aborto poderia ser permitido ou proibi-lo totalmente. Em todas as } \\
\text { pesquisas, a maior parcela de eleitores foi sempre a favor da manutenção da lei atual. Com uma única exceção, mais da metade dos entrevistados indicou essa } \\
\text { opção. Aqui, como havia mais de duas opções, não calculamos o diferencial. } \\
\text { (3) Perguntas: se a favor ou contra a lei do planejamento familiar; ou se contra ou a favor de fornecimento de preservativos e remédios anticoncepcionais, DIU } \\
\text { e outros mecanismos para contracepção. }\end{array}$} \\
\hline
\end{tabular}


O número de meses que consideramos como de congruência ( $3^{\mathrm{a}}$ coluna da tabela) foi calculado tomando-se como início o mês da primeira pesquisa em que determinada posição é majoritária em relação a um tema, e como final o mês em que houve alguma mudança (na opinião majoritária ou na legislação). Caso não tenha havido nenhuma mudança, o mês final considerado é setembro de 2017 (momento em que encerramos nossa pesquisa). Por exemplo: entre 2008 e 2017, foram aplicadas 10 pesquisas com perguntas relativas à pena de morte e, em todas elas, houve uma maioria dos cidadãos contra a aprovação dessa medida (aprovação que realmente não ocorreu). 114 é o número de meses entre março de 2008, mês em que ocorreu a $1^{\text {a }}$ pesquisa desse período, e setembro de 2017. A "suposição" é a de que, durante todo esse período, havia uma maioria querendo a manutenção da legislação. Sabemos que suposição semelhante (relativa a uma posição predominante ao longo de período longo de tempo) é frágil para os casos em que há poucas pesquisas. De toda forma, para manter um critério único, mantivemos o mesmo procedimento para o cálculo, qualquer que tenha sido o número de pesquisas relativas a cada tema. $\mathrm{Na}$ análise atual, daremos ênfase apenas aos casos em que a suposição pode ser mais sustentável.

Em relação à área de segurança pública, cabe mencionar, como dois casos de congruência entre a legislação em vigor e a opinião majoritária da população, os da pena de morte e da proibição (ou não legalização) do uso de drogas. Quanto ao primeiro, como será visto mais adiante, foi o tema em que houve maior variação na opinião majoritária ao longo do período. Para o período entre 2008 e 2017, no entanto, nas 11 pesquisas de que dispomos, a maioria foi contra a introdução da pena de morte. Em 16 pesquisas entre 1995 e 2017, a população mostrou-se também majoritariamente a favor da proibição do uso de drogas.

Inclui-se na mesma situação a maior parte dos casos relacionados com o tema do aborto. Na legislação brasileira, o aborto é considerado crime, conforme está disposto no Código Penal (Decreto-lei $n^{\circ}$ 2.848), de 1940. Apenas não é crime em duas situações: em caso de risco a vida da gestante e em caso de gravidez resultante de estupro. Nesses casos, a mulher pode escolher ou não escolher abortar; caso decida favoravelmente, o procedimento deve ser realizado gratuitamente pelo Sistema Único de Saúde (SUS) - tópico que foi regulamentado mais recentemente. Temos disponível um grande conjunto de questões relativas à opinião dos cidadãos sobre o aborto, em diferentes situações. Como se pode ver na Tabela 2, na grande maioria das vezes, a população concorda com a legislação vigente: contra a legalização do aborto em geral e em todas as situações ali sugeridas, com exceção do aborto em caso de risco à vida da mulher (caso em que a maioria se coloca a favor, também em conformidade com a lei). Os casos de incongruência serão apresentados e analisados mais à frente, na Tabela 4 - o do aborto quando a mulher tem AIDS e quando o feto enfrenta problema grave. Nas pesquisas sobre esse último tema, incluídas na Tabela 4 (em que a maioria aceitava que o aborto deveria ser permitido ou legalizado e, por isso, consideramos como caso de incongruência), as perguntas faziam menção ao feto ter "problema físico ou mental" grave ou "grandes chances de o bebê nascer com defeitos graves". A pergunta incluída aqui, na Tabela 2, mencionava, especificamente, a "microcefalia durante a gravidez de mulheres que tiveram zika" e, nesse caso, como a maioria era contra, a legislação (que não permite o aborto nesse caso) era congruente com a opinião majoritária dos cidadãos. Não é possível avaliar se houve mudança na posição da maioria em relação ao tema, já que os enunciados não são totalmente comparáveis. Vale notar que, em 2012, o Supremo Tribunal Federal (STF) decidiu que grávidas de fetos sem cérebro (anencefalia) poderão optar por interromper a gestação com assistência médica. Essa medida foi encaminhada, no mesmo ano, à Câmara de Deputados, como projeto de decreto legislativo, mas até hoje não foi votada. 
Em relação ao tema do aborto em casos de gravidez resultante de violência sexual, estupro, as três pesquisas, realizadas na metade dos anos 90 e mostradas na Tabela 2, revelam uma maioria em consonância com a legislação em vigor. Outra pesquisa, porém, realizada em 2005 (apresentada na Tabela 4), mostra uma pequena maioria contra a prática do aborto em caso de violência sexual. Aqui também é difícil dizer se houve uma mudança na opinião da maioria, já que essa mudança pode ser devida (ao menos parcialmente) a mudanças no enunciado das questões. Enquanto nos casos apresentados na Tabela 2 o entrevistado era perguntado se achava que o aborto deveria ser "permitido" ou "legalizado" em caso de violência sexual, no caso apresentado na Tabela 4, a pergunta era se o entrevistado era "a favor ou contra a prática do aborto" nesse tipo de situação. ${ }^{13}$

Embora com base em poucas pesquisas, também em muitos outros temas, a maioria da população manifestou, como se pode ver na Tabela 2, uma opinião em consonância com a legislação em vigor: contra a cobrança de mensalidades em universidades públicas ${ }^{14}$, contra a recriação da CPMF - em 3 ocasiões (2007, 2010 e 2015/16) em que essa proposta ressurgiu no debate público, por iniciativa de governadores ou da presidência da República ${ }^{15}$ - e, na área do of trabalho, posicionando-se contra, entre outras Nิ medidas: a criação de cotas raciais em novelas,

${ }^{13}$ Além disso, embora não tenhamos considerado aqui, por ส] ter sido feita por telefone, pesquisa Ibope aplicada em ju$\sum$ nho de 2007 mostrava uma pequena maioria (49\% x 43\%)

ळi a favor da possibilidade de aborto em caso de estupro, o ๆ que inverteria a tendência indicada pela pesquisa de 2005.

${ }^{14}$ Numa pesquisa de 2010, houve “empate técnico”, em i. relação à pergunta: "Como os recursos são limitados, as

o universidades públicas deveriam ser pagas para que o

$\infty$ governo tivesse mais condições de investir na educação

¿ fundamental e no ensino médio (concorda/discorda?)".

i Nas demais (sem menção a recursos limitados) a maioria

. era contra a cobrança da mensalidade. Como há variações

$>$ muito grandes nas respostas de acordo com o enunciado

ธิ das perguntas, preferimos não calcular diferencial médio.

${ }^{15} \mathrm{O}$ decreto $\mathrm{n}^{\mathrm{O}}$ 6140/07, que regulamentava a CPMF, defiస nia a vigência do imposto até 31 de dezembro de 2007 . Na - pesquisa feita em setembro de 2007, a maioria da popuIação foi contra a possibilidade de renovação do imposto

U (que não foi, realmente, renovado, terminado aquele pra-

zo). Outras pesquisas, em 2010, 2015 e 2016 foram feitas, em ocasiões em que havia menções à recriação da CPMF, seja por parte de governadores ou da presidência. Em to-

đ das, a maioria da população se mostrou contra. filmes e propagandas, a proibição de greves, a redução do período de férias, a retirada do adicional de férias, o fim da indenização em caso de demissão, o fim da contribuição obrigatória para a Previdência, a transformação de encargos do Seguro de Acidentes de Trabalho em repasse direto para os trabalhadores e a possibilidade legal de redução de jornada de trabalho com redução de salário. Esse último caso é complexo. A Constituição Federal, em seu artigo $7^{\circ}$, inciso VI, prevê a possibilidade de redução salarial mediante convenção ou acordo coletivo. O artigo 468 da CLT, por sua vez, determina que "nos contratos individuais de trabalho, só é lícita a alteração das respectivas condições por mútuo consentimento, e, ainda assim, desde que não resultem, direta ou indiretamente, prejuízos ao empregado, sob pena de nulidade da cláusula infringente dessa garantia”. Andrade (1986, p.147), interpretando esse artigo, afirma que "a norma geral do [...] art. 468 [...] consagrou o princípio da irredutibilidade do salário. Comprovado o prejuízo, presume-se que o consentimento do trabalhador foi obtido mediante falsa manifestação de vontade." Consideramos aqui essa última interpretação e, havendo uma pesquisa realizada em 1996, em que a maioria dos cidadãos se mostrava contrária a essa possibilidade, consideramos como um caso de congruência.

Um terceiro tipo de congruência é mostrado na Tabela 3: são casos de aprovação, por parte do público, de mudanças feitas na legislação pouco tempo antes (no máximo, dois anos antes da pesquisa de opinião em pauta).

Os casos foram: i) o monitoramento eletrônico de presidiários, com uma pesquisa feita em julho de 2011 que mostrava a concordância da maioria dos entrevistados com a lei que havia aprovado essa medida dois meses antes; ii) as penas alternativas, aprovadas numa lei de junho de 2016, com uma pesquisa feita em março de 2008 e outra feita em 2011 mostrando concordância da maioria; iii) a propaganda de cigarro com imagens (lei aprovada em Agosto de 2001; maioria a favor - Abril de 2002); iv) os direitos trabalhistas dos empre- 
Tabela 3 - Tipo 3. Congruência: casos em que uma pesquisa é aplicada após uma mudança da legislação, mostrando que a maioria do público a aprovou

\begin{tabular}{|c|c|c|c|c|c|}
\hline $\begin{array}{l}\text { Área } \\
\text { Temática }\end{array}$ & Tema, posição majoritária, data das pesquisas e da legislação & $\begin{array}{c}\mathrm{N}^{0} \text { de meses } \\
\text { entre lei e } \\
\text { pesquisa (1) }\end{array}$ & $\begin{array}{c}\text { Diferencial } \\
\text { médio } \\
(\%)\end{array}$ & $\begin{array}{l}\text { NS, NR } \\
(\%)\end{array}$ & $\begin{array}{c}\mathrm{N}^{\mathrm{o}} \mathrm{de} \\
\text { pesquisas }\end{array}$ \\
\hline \multirow{2}{*}{$\begin{array}{l}\text { Segurança } \\
\text { Pública }\end{array}$} & $\begin{array}{l}\text { Monitoramento eletrônico de presidiários (maioria a favor; julho de 2011; lei alterada } \\
\text { em maio de 2011) }\end{array}$ & 2 & 69,0 & 9,0 & 1 \\
\hline & Penas alternativas (maioria a favor; 2008 - 2011; lei alterada em 2006) & 21 & 61,0 & 5,0 & 3 \\
\hline Saúde & $\begin{array}{l}\text { Propaganda de cigarro com imagens (maioria a favor; abril de 2002; lei aprovada em } \\
\text { agosto de 2001)(2) }\end{array}$ & 9 & 60,2 & 6,6 & 1 \\
\hline \multirow{2}{*}{ Educação } & $\begin{array}{l}\text { Cotas sociais para ingresso em universidades públicas(3) (maioria a favor; janeiro de } \\
\text { 2013; aprovação da legislação: agosto de 2012). }\end{array}$ & 5 & 58,0 & 4,0 & 1 \\
\hline & $\begin{array}{l}\text { Cotas raciais para ingresso em universidades públicas(3) (maioria a favor; janeiro de } \\
\text { 2013; aprovação da legislação: agosto de 2012). }\end{array}$ & 5 & 32,0 & 4,0 & 1 \\
\hline Trabalho & $\begin{array}{l}\text { Direitos trabalhistas dos empregados domésticos(4) (maioria a favor; maio de 2013; } \\
\text { aprovação da legislação: abril de /2013). }\end{array}$ & 1 & 88,0 & 6,0 & 1 \\
\hline
\end{tabular}

Fonte: Banco de Opiniões dos Eleitores sobre Políticas Públicas (Necip, UFSC). Elaboração nossa.

(1) Aqui, apenas se indica o número de meses entre a aprovação da lei e a expressão da opinião do público (aprovando), em pesquisa.

(2) A Medida Provisória No 2.190-34, de Agosto de 2001, modifica a Lei 9.294, de Julho de 1996, instituindo que "as embalagens e os maços de produtos fumígenos, com exceção dos destinados à exportação, e o material de propaganda [...] conterão a advertência mencionada no § 2o [sobre os riscos para a saúde] acompanhada de imagens ou figuras que ilustrem o sentido da mensagem".

(3) Antes de ocorrer a aprovação dessas medidas (cotas sociais e raciais para ingresso nas universidades), em 2012, já havia pesquisas bem anteriores (2003/8) que mostravam a concordância da maioria dos cidadãos com elas. De acordo com o critério estabelecido mais acima, classificamos também essas situações (relativas ao período 2003-2008) como casos de incongruência (como será visto na Tabela 4).

(4) A pergunta era: "O(a) sr(a) diria que aprova ou desaprova as novas regras definidas na PEC das Domésticas?"

gados domésticos, em que uma pesquisa feita, um mês após a aprovação da "PEC das domésticas", em abril de 2013, confirmou o amplo apoio da população àquela PEC; v e vi) cotas sociais e raciais para ingresso em universidades públicas, medidas aprovadas em agosto de 2012 e que tiveram apoio da maioria em pesquisa de janeiro de 2013.

Aproveitamos, aqui, para tratar do problema das "respostas socialmente desejáveis". Embora haja algum risco em tomar as respostas dos entrevistados por seu valor de face, decidimos agir dessa forma porque, de um lado, julgamos que não é evidente qual é a "resposta socialmente desejável" em relação a determinada pergunta; além disso, avaliamos que as relações entre as respostas de entrevistados e suas "opiniões sinceras" a respeito de temas "sensíveis" como esses podem ser mais complexas do que a mera existência de um contingente de pessoas que, por exemplo, afirma ser a favor das cotas embora, na realidade, seja contrário a elas. O estudo de Turgeon, Chaves e Wives (2014), por exemplo, mostra tendência em direção diferente dessa. Aplicando o chamado "experimento de listas" em um survey entre estudantes da Universidade de Brasília (para tentar estimar as “opiniões sinceras” dos estudantes acerca do sistema de cotas raciais como mecanismo de seleção de estudantes na universidade), os autores concluem:

[...] os resultados mostraram que o viés nas opiniões ocorreu, de forma inesperada, no grupo de estudantes elegíveis às cotas (afrodescendentes e indígenas). Precisamente, eles apoiaram fortemente o sistema de cotas raciais $(68,3 \%)$ quando tiveram privacidade nas respostas, mas, na pergunta direta, demonstraram apenas uma tímida aprovação $(29,0 \%)$. Chamamos esse efeito de efeito de inibição. Paralelamente, os estudantes brancos não demonstraram nenhum efeito de desejabilidade social, contrariando alguns achados de pesquisas similares nos EUA (Turgeon; Chaves; Wives, 2014, p. 363).

A Tabela 4 apresenta um primeiro tipo de casos de incongruência: são casos em que, embora a opinião majoritária fosse a favor de uma mudança na legislação em vigor, essa mudança não ocorreu.

O número de meses que consideramos como de incongruência foi calculado tomando como início o mês da primeira pesquisa em que determinada posição é majoritária em relação a um tema (e em contradição com a legislação vigente), e como final o mês em que houve alguma mudança (na opinião majoritária ou na 
Tabela 4 - Tipo 4. Incongruência: casos em que não houve mudança da legislação, quando havia apoio manifesto por essa mudança

\begin{tabular}{|c|c|c|c|c|c|}
\hline $\begin{array}{l}\text { Área } \\
\text { Temática }\end{array}$ & $\begin{array}{l}\text { Tema, posição majoritária, data das pesquisas } \\
\text { (e da legislação, quando houve, tardiamente) }\end{array}$ & $\begin{array}{c}\mathrm{N}^{\mathrm{o}} \text { de meses } \\
\text { incongruente }^{(1)}\end{array}$ & $\begin{array}{c}\text { Diferencial } \\
\text { médio } \\
(\%)\end{array}$ & $\begin{array}{l}\text { NS, NR } \\
(\%)\end{array}$ & $\begin{array}{l}\mathrm{N}^{0} \text { de } \\
\text { pesquisas }\end{array}$ \\
\hline \multirow{7}{*}{$\begin{array}{l}\text { Segurança } \\
\text { Pública }\end{array}$} & Redução da idade da maioridade penal (maioria a favor, 2002 - 2015) & 177 & 64,8 & 2,7 & 21 \\
\hline & Pena de morte (maioria a favor, 1991 - 1997) & 74 & 8,8 & 5,9 & 4 \\
\hline & Prisão perpétua (maioria a favor, 2002 - 2011) & 187 & 41,3 & 5,1 & 6 \\
\hline & Unificação das polícias (maioria a favor, 2001 - 2011) & 193 & 51,5 & 11,3 & 4 \\
\hline & Greves policiais (maioria a favor, 2001) & 193 & 14,4 & 6,1 & 1 \\
\hline & Uso de Forças Armadas na segurança pública (maioria a favor, 2000 -2014) & 207 & 64,2 & 3,5 & 9 \\
\hline & Regime Disciplinar Diferenciado (maioria contra, 2006) & 133 & 34,1 & 4,5 & 1 \\
\hline \multirow{4}{*}{ Saúde } & $\begin{array}{l}\text { Aborto quando o feto apresenta problema grave (maioria a favor, janeiro de } 1991 \text { - } \\
\text { junho de 2002) }\end{array}$ & 320 & 26,7 & 5,2 & 6 \\
\hline & Aborto em caso de violência sexual (abril de 2005) & 149 & 6 & 7 & 1 \\
\hline & Aborto. Gestante com AIDS (maioria a favor, setembro de 1991 - setembro de 1993) & 312 & 51,7 & 5,2 & 2 \\
\hline & Proibição de propaganda de bebidas (maioria a favor, abril de 2003) & 173 & 48,3 & 5,2 & 1 \\
\hline \multirow{4}{*}{ Educação } & $\begin{array}{l}\text { Cotas sociais para ingresso em universidades públicas (maioria a favor; setembro } \\
\text { de 2003; aprovação da legislação: agosto de 2012) }\end{array}$ & 107 & $(--)$ & 5,0 & 1 \\
\hline & $\begin{array}{l}\text { Cotas sociais para ingresso em faculdades particulares (maioria a favor, setembro } \\
\text { de 2003; aprovação da legislação: agosto de 2012) }\end{array}$ & 107 & $(--)$ & & \\
\hline & $\begin{array}{l}\text { Cotas raciais para ingresso em universidades públicas (maioria a favor, maio de } \\
2004,2008 \text {; aprovação da legislação: agosto de 2012). }\end{array}$ & 6,0 & 1 & & \\
\hline & $\begin{array}{l}\text { Cotas raciais para ingresso em universidades particulares (maioria a favor, } \\
\text { setembro de 2008) }\end{array}$ & 101 & 31,7 & 9,6 & 2 \\
\hline \multirow{8}{*}{ Trabalho } & $\begin{array}{l}\text { Cotas raciais para empregos públicos (maioria a favor, dezembro de 2002; setembro } \\
\text { de 2008; aprovação da legislação: junho de 2014). }\end{array}$ & 139 & 21,7 & 5,3 & 2 \\
\hline & Cotas raciais para empresas privadas (maioria a favor, setembro de 2008) ${ }^{(4)}$ & 168 & (4) & 3,7 & 1 \\
\hline & $\begin{array}{l}\text { FGTS para empregados domésticos (maioria a favor, agosto de 2006; aprovação da } \\
\text { legislação: abril de 2013). }\end{array}$ & 81 & 83,8 & 4,0 & 1 \\
\hline & $\begin{array}{l}\text { Livre negociação (maioria a favor, janeiro e agosto de 1990; 1996; 1997; 1998; } \\
\text { aprovação da legislação: julho de 2017) }\end{array}$ & 326 & 47,5 & 10,4 & 5 \\
\hline & $\begin{array}{l}\text { Substituição de tíquetes-refeição por auxílio em dinheiro (maioria a favor, agosto } \\
\text { de 1995) }\end{array}$ & 265 & 28,8 & 4,3 & 1 \\
\hline & $\begin{array}{l}\text { Transformar encargos do Salário-Educação em repasse direto aos trabalhadores } \\
\text { (maioria a favor, janeiro de 2002) }\end{array}$ & 188 & 8,0 & 4,9 & 1 \\
\hline & $\begin{array}{l}\text { Fim da estabilidade de funcionários públicos (maioria a favor, fevereiro e agosto } \\
\text { de 1996) }\end{array}$ & 210 & 8,7 & 11,3 & 2 \\
\hline & Limitação ao trabalho de imigrantes ${ }^{(2)}$ (maioria a favor, dezembro de 2006) & 129 & 79,8 & 2,3 & 1 \\
\hline $\begin{array}{l}\text { Fonte: Banco } \\
\text { (1) Vale aqui } \\
\text { (2) "Impor lin } \\
\text { das a favor d } \\
\text { legislaç } \\
\text { mudan } \\
\text { de } 2017 \\
\text { aplicad } \\
\text { ao tema } \\
\text { dos cid }\end{array}$ & $\begin{array}{l}\text { de Opiniões dos Eleitores sobre Políticas Públicas (Necip, UFSC). Elaboração nossa. } \\
\text { mesma ressalva feita na Nota } 1 \text { da Tabela } 2 \text {. } \\
\text { ites ao número de estrangeiros que podem vir" e "deixar que as pessoas venham, desde } \\
\text { limites à liberdade de trabalho para imigrantes. } \\
\text { ăo). Caso não tenha havido nenhuma dade penal } \\
\text { a, o mês final considerado é setembro dezembro } \\
\text { Por exemplo, entre } 2002 \text { e } 2015 \text { foram histórica, e } \\
\text { e, em todas elas, houve uma maioria maioria que } \\
\text { adãos favorável à redução da maiori- mudança n }\end{array}$ & $\begin{array}{l}\text { que haja empregos } \\
177 \text { é o r } \\
\text { e } 2002 \text {, pri } \\
\text { setembro d } \\
\text { ante todo e } \\
\text { rendo muc } \\
\text { io ocorreu. }\end{array}$ & $\begin{array}{l}\text { disponíveis" } \\
\text { ú́mero c } \\
\text { meira pe } \\
\text { e } 2017 . \\
\text { sse períc } \\
\text { lança na }\end{array}$ & $\begin{array}{l}\text { ram respo } \\
\text { e mes } \\
\text { suisa } \\
\text { do, ha } \\
\text { legisla }\end{array}$ & $\begin{array}{l}\text { tas consiera- } \\
\text { s entre } \\
\text { da série } \\
\text { ição é a } \\
\text { jia uma } \\
\text { ção, e a }\end{array}$ \\
\hline
\end{tabular}


O caso mais claro de desconsideração, pelo Congresso, da opinião do eleitorado brasileiro parece ser o da proposta de redução da maioridade penal. Conforme o artigo 228 da Constituição Federal, "são penalmente inimputáveis os menores de dezoito anos, sujeitos às normas da legislação especial”. A afirmação é reforçada pelo artigo 27 do Código Penal, e pelos artigos 102 e 104 do Estatuto da Criança e do Adolescente (ECA, Lei $\mathrm{n}^{0}$ 8.069/90). No entanto, 21 pesquisas entre 2002 e 2015 revelam uma ampla, generalizada e contínua maioria da população a favor da redução da maioridade penal. ${ }^{16}$ Desde a primeira dessas pesquisas até hoje, já se passaram 177 meses (cerca de 15 anos), sem que o Congresso tenha aprovado uma mudança nessa legislação. Há vários fatores que fazem com que qualquer modificação dessa lei seja difícil: entre outros, alterações da Constituição, que passam por um processo legislativo mais árduo e, como muitos juristas afirmam que a cláusula que define a maioridade penal é uma "cláusula pétrea", o Supremo Tribunal Federal poderia, em última instância, decidir sobre qualquer modificação.

Vários outros casos relativos à segurança pública se enquadram nesse tipo: prisão perpétua, unificação das polícias, greves de policiais e uso das Forças Armadas na segurança pública. Em todos esses casos, embora a população se manifestasse majoritariamente a favor, nenhuma dessas medidas foi aprovada. A consideração do uso das Forças Armadas no combate à criminalidade, como congruente ou incongruente, é de difícil enquadramento. Nas nove pesquisas disponíveis sobre o tema, entre 1994 e 2014, há uma ampla maioria favorável à medida. Se a pergunta é compreendida pelo público como o emprego excepcional das For-

${ }^{16}$ Há variações nas perguntas: algumas mencionam a "prisão para menores de idade", outras a "redução da maioridade penal", ou ainda "adolescentes que cometem crimes devem ser punidos como adultos". Em todas elas, porém, a grande maioria dos entrevistados era favorável a (ou concordava com) essas opções. A diferença média entre a porcentagem dos entrevistados a favor e a porcentagem dos contra, nas 21 pesquisas, foi de 64,8\%. Além disso, nas pesquisas em que foi possível desagregar os dados, pudemos verificar que o apoio à redução da maioridade penal é majoritário em todas as faixas de renda familiar. ças Armadas no combate a algo que coloque em risco a ordem pública, deveríamos considerar esse caso como de congruência, já que se pode interpretar que a legislação permite esse uso. Por outro lado, se a pergunta é compreendida como o uso permanente das Forças Armadas como força policial (policiamento ostensivo permanente, por exemplo), então consideramos que a legislação é incongruente, uma vez que as Forças Armadas são convocadas apenas em situações excepcionais, e não empregadas por padrão no controle diário da ordem pública, atribuição da Polícia Militar. Considerando que a forma como as perguntas foram feitas permite a interpretação de que se trata do uso permanente das Forças Armadas no combate à violência, optamos por considerar incongruente a legislação no que concerne à opinião da maioria dos cidadãos. Reconhecemos, porém, que esse é um caso de difícil classificação em nossa tipologia.

Já foram mencionados também, além do caso do aborto quando a gravidez foi originada em violência sexual (em que, em uma pesquisa, a maioria foi contra a possibilidade da prática do aborto), os casos de aborto quando o feto apresenta problemas graves ou na situação em que a mulher tem AIDS. Nesses casos, a maioria da população é favorável à prática do aborto, em dissonância com a lei vigente. Inversamente, enquadramos aqui também os casos de cotas sociais ${ }^{17}$ e raciais ${ }^{18}$ para ingresso nas universidades durante o período 2003-

17 A pergunta oferecia 3 opções: cotas sociais (estudantes de escola pública), cotas raciais e nenhuma cota. Como $55 \%$ foram favoráveis às cotas sociais, optamos por considerar essa questão, mas não calculamos o diferencial. Outras duas pesquisas, de setembro e novembro de 2008, perguntavam se os entrevistados eram contra ou a favor das cotas sociais (para estudantes pobres ou de escola pública), sem especificar se para universidades públicas ou privadas. De toda forma, nas duas pesquisas havia uma ampla maioria favorável (diferencial médio de 66\%).

${ }^{18}$ Consideramos, aqui, uma pesquisa que mencionava "universidades públicas" e outra que mencionava "universidades públicas e particulares”, considerando que, nessa última, a resposta era válida para a opinião sobre os dois tipos de universidades. Nas duas, havia uma maioria favorável e, por isso, consideramos como dois "casos": um relativo às públicas (com duas pesquisas) e outro relativo a universidades privadas (com uma pesquisa), com apoio da maioria. Não calculamos o diferencial no caso da pesquisa que mencionava os dois tipos de universidade simultaneamente. 
2008, já que esse tipo de medida só foi materializado na forma de lei em 2012. Valem, aqui, as ressalvas já feitas sobre o possível risco de tomar opiniões sobre temas socialmente delicados como esse, por seu valor de face. Por fim, vários casos relativos a temas trabalhistas também se encaixam nessa situação. Embora, em algum momento, a população tenha expressado, em uma ou mais pesquisas, ser favorável a medidas como cotas raciais para emprego em empresas privadas, ${ }^{19}$ substituição de tíquetes-refeição por auxílio em dinheiro, transformar encargos da contribuição para a Previdência ou do Salário-Educação em repasse direto aos trabalhadores, fim da estabilidade de funcionários públicos, ou a limitação ao trabalho de imigrantes, nenhuma dessas medidas foi aprovada. Em outros casos, como os das cotas raciais para empregos públicos, da "livre negociação" entre empregados e empregadores ${ }^{20} \mathrm{ou}$ do FGTS para empregados domésticos, embora essas medidas acabassem por ser aprovadas, isso aconteceu em período bem posterior (mais de 48 meses depois) à manifestação da opinião majoritária dos cidadãos (e, por isso, foram enquadrados aqui como casos de incongruência).

Outros casos de incongruência são aqueles em que o Congresso acabou por aprovar legislação que ia contra a opinião majoritária dos cidadãos (Tabela 5).

Aqui, medimos o número de meses entre a última manifestação da preferência dos eleitores e a aprovação da lei (em discordância com aquela maioria), de forma a dar uma ideia se já havia se passado muito tempo e, portanto, mesmo que os representantes se preocupassem com a opinião da maioria dos eleitores, talvez não pudessem mais ter qualquer segurança de que ela ainda seria a opinião majoritária, àquela altura. No caso da Lei de Biossegurança (Lei 11.105, de março de 2005), 27 meses depois da pesquisa de dezembro de 2002, em que a maioria dos eleitores se mostrou contrária, os legisladores foram contra essa manifestação ao aprovar o plantio de transgênicos. No caso da CPMF, a lei foi aprovada sete meses após a primeira pesquisa e quatro meses após a segunda; em ambas, a maioria da população rejeitava a CPMF.

Tabela 5 - Tipo 5. Incongruência: casos em que o Congresso aprova uma legislação em relação à qual a maioria dos cidadãos é contra

\begin{tabular}{|c|c|c|c|c|c|c|}
\hline $\begin{array}{l}\text { Área } \\
\text { Temática }\end{array}$ & \multicolumn{2}{|c|}{ Tema, posição majoritária, data das pesquisas e da legislação } & $\begin{array}{c}\mathrm{N}^{0} \text { meses } \\
\text { entre } \\
\text { opinião e } \\
\text { mudança na } \\
\text { legislação }\end{array}$ & $\begin{array}{l}\text { Diferencial } \\
\text { médio } \\
(\%)\end{array}$ & $\begin{array}{c}\text { NS, NR } \\
(\%)\end{array}$ & $\begin{array}{c}\mathrm{N}^{\circ} \text { de } \\
\text { pesquisas }\end{array}$ \\
\hline \multirow{2}{*}{ Saúde } & \multicolumn{2}{|c|}{$\begin{array}{l}\text { Transgênicos - plantio (maioria contra; julho de } 2001 \text { - dezembro de 2002; Lei de } \\
\text { Biossegurança aprovada em março de 2005). }\end{array}$} & 27 & 46,7 & 14,3 & 3 \\
\hline & \multicolumn{2}{|c|}{$\begin{array}{l}\text { Imposto para saúde (CPMF - CSS) - criação (maioria contra. março e junho de 1996; } \\
\text { Lei 9.311, aprovada em outubro de 1996). }\end{array}$} & 4 & 23,8 & 8,1 & 2 \\
\hline Trabalho & \multicolumn{2}{|c|}{$\begin{array}{l}\text { "Livre negociação"(1) (maioria contra; abril de 2017; aprovação da legislação em julho } \\
\text { de 2017) }\end{array}$} & 3 & 30,0 & 10,0 & 1 \\
\hline \multicolumn{7}{|c|}{$\begin{array}{l}\text { Fonte: Banco de Opiniões dos Eleitores sobre Políticas Públicas (Necip, UFSC). Elaboração nossa. } \\
\text { (1) A pergunta (do Datafolha) era: "Na sua opinião, o que é melhor para as relações entre empresários e trabalhadores: que as condições de trabalho, como } \\
\text { jornada diária, período de férias e banco de horas, sejam definidas por uma lei trabalhista; que empresários e trabalhadores negociem e definam entre eles as } \\
\text { condições de trabalho, como jornada diária, período de férias e banco de horas" (respostas: } 60 \% \text { e } 30 \% \text {, respectivamente; NS/NR: } 10 \% \text { ). }\end{array}$} \\
\hline \multicolumn{2}{|c|}{$\begin{array}{l}{ }^{19} \text { Uma das pesquisas perguntava a opinião relativa a co- } \\
\text { tas raciais em empresas públicas e privadas. Operaciona- } \\
\text { lizamos a análise da mesma forma apontada na Nota } 32 \text {. } \\
\text { Outra pesquisa mencionava cotas raciais em "empresas e } \\
\text { serviços públicos"; como há uma dubiedade, podendo o } \\
\text { enunciado ser interpretado como se referindo a empresa } \\
\text { privada e serviço público ou empresa pública e serviço } \\
\text { público, optamos por não considerar no cálculo do dife- } \\
\text { rencial. De toda forma, a maioria também se mostrou fa- } \\
\text { vorável às cotas. }\end{array}$} & $\begin{array}{l}\text { O pri } \\
\text { vação, na L( } \\
\text { 2005), da p } \\
\text { nismos) traı } \\
\text { realizadas e } \\
\text { maioria sign }\end{array}$ & $\begin{array}{l}\text { eiro des } \\
\text { de Bios } \\
\text { sibilidac } \\
\text { gênicos, } \\
\text { re } 2001 \\
\text { icativa c }\end{array}$ & $\begin{array}{l}\text { ses casos } \\
\text { legurança de pla } \\
\text { quando } \\
\text { e } 2002 \mathrm{~m} \\
\text { ontrária }\end{array}$ & $\begin{array}{l}\text { é o } \\
\text { (de } \mathrm{n} \\
\text { ntio } \mathrm{c} \\
\text { rês p } \\
\text { ostrav } \\
\text { esse p }\end{array}$ & $\begin{array}{l}\text { apro- } \\
\text { arço de } \\
\text { (orga- } \\
\text { squisas } \\
\text { m uma } \\
\text { antio. }\end{array}$ \\
\hline \multicolumn{2}{|c|}{$\begin{array}{l}{ }^{20} \text { Há vários enunciados de perguntas referentes à "livre } \\
\text { negociação" entre patrões e empregados, mas, nas quatro } \\
\text { pesquisas entre } 1990 \text { e } 1998 \text {, a maioria era favorável, qual- } \\
\text { quer que fosse o enunciado. }\end{array}$} & $\begin{array}{l}21 \text { A pergunta, } \\
\text { há divergências } \\
\text { cos dos organis } \\
\text { para a saúde hy }\end{array}$ & $\begin{array}{l}\text { três pes } \\
\text { a comun } \\
\text { ps transg }\end{array}$ & $\begin{array}{l}\text { isas, era: ' } \\
\text { ade científ } \\
\text { icos para } \\
\text { (a) sr(a) a }\end{array}$ & $\begin{array}{l}\text { onsid } \\
\text { a qua } \\
\text { meio }\end{array}$ & $\begin{array}{l}\text { ndo que } \\
\text { aos ris- } \\
\text { biente e } \\
\text { veria ser }\end{array}$ \\
\hline
\end{tabular}


O segundo caso é o da criação da CPMF, em outubro de 1996, quando duas pesquisas anteriores, naquele mesmo ano, mostravam também ampla reprovação do público. Por fim, o terceiro caso é o da aprovação da "livre negociação" entre empregadores e empregados, na recente "Reforma Trabalhista" (Lei $\mathrm{n}^{\mathrm{O}}$ 13.467, de julho de 2017), quando 3 meses antes, em pesquisa do Datafolha, 60\% dos entrevistados diziam preferir "que as condições de trabalho, como jornada diária, período de férias e banco de horas, sejam definidas por uma lei trabalhista”, contra apenas 30\% que preferiam que "empresários e trabalhadores negociem e definam entre eles as condições de trabalho."

Por fim, cabe menção a um tema importante, que envolve mais de um "caso", tal como foi aqui definido: a pena de morte. ${ }^{22}$ Como já foi mencionado mais acima, houve muita variação na opinião majoritária da população ao longo do tempo: das 31 pesquisas entre $1991 \mathrm{e}$ 2017, temos um primeiro período entre 1991 e 1997, em que 4 pesquisas disponíveis apontavam uma maioria a favor da pena de morte (caso de incongruência, portanto, já que nossa Constituição não prevê a pena de morte); num segundo período entre 1997 e 2008, 17 pes- quisas foram feitas, com várias mudanças na opinião majoritária (em períodos sempre bem menores do que quatro anos, razão pela qual não foram consideradas na análise de congruência); por fim, um terceiro período, entre 2008 e 2017, em que, nas 10 pesquisas disponíveis, a maioria se mostrou contra a pena de morte (caso de congruência). Um dado importante é o de que, mesmo num período (como o primeiro) em que a maioria da população se mostrou favorável, o diferencial médio entre a porcentagem de pessoas na posição majoritária e a porcentagem na posição minoritária foi em torno de 8,8\%; na realidade, em momento algum houve uma maioria muito ampla a favor ou contra a implantação da pena de morte. Além disso, a aprovação desse tipo de medida é extremamente difícil, dado que seria necessária uma emenda em relação a uma cláusula da Constituição que muitos juristas consideram "pétrea". Uma mudança dessa natureza provavelmente seria contestada junto ao Supremo Tribunal Federal (STF), gerando insegurança jurídica. ${ }^{23}$

A Tabela 6 sintetiza os principais dados das tabelas anteriores, apresentando os totais de casos para cada tipo criado, segundo a área temática.

Tabela 6 - Síntese dos dados: número de casos de cada tipo

\begin{tabular}{|c|c|c|c|c|c|c|c|c|}
\hline \multirow[b]{3}{*}{$\begin{array}{l}\text { Área } \\
\text { Temática }\end{array}$} & \multicolumn{4}{|c|}{ Congruência } & \multicolumn{3}{|c|}{ Incongruência } & \multirow[b]{3}{*}{ Total } \\
\hline & 1 & 2 & 3 & & 4 & $\mathbf{5}$ & & \\
\hline & $\begin{array}{c}\text { Mudança na } \\
\text { legislação, } \\
\text { seguindo opinião } \\
\text { (a favor da } \\
\text { mudança) }\end{array}$ & $\begin{array}{c}\text { Sem mudança } \\
\text { na legislação, } \\
\text { seguindo opinião } \\
\text { (contra a } \\
\text { mudança) }\end{array}$ & $\begin{array}{c}\text { Maioria aprova } \\
\text { mudança recente } \\
\text { da legislação }\end{array}$ & Total & $\begin{array}{c}\text { Sem mudança } \\
\text { na legislação, } \\
\text { contrariando } \\
\text { opinião (a favor da } \\
\text { mudança) }\end{array}$ & $\begin{array}{c}\text { Mudança na } \\
\text { legislação, } \\
\text { contrariando } \\
\text { opinião (contra a } \\
\text { mudança) }\end{array}$ & Total & \\
\hline $\begin{array}{l}\text { Segurança } \\
\text { Pública }\end{array}$ & -- & 3 & 2 & 5 & 7 & -- & 7 & 12 \\
\hline Saúde & 3 & 12 & 1 & 16 & 4 & 2 & 6 & 22 \\
\hline Educação & -- & 1 & 2 & 3 & 4 & -- & 4 & 7 \\
\hline Trabalho & -- & 14 & 1 & 15 & 8 & 1 & 9 & 24 \\
\hline Total & 3 & 30 & 6 & 39 & 23 & 3 & 26 & 65 \\
\hline$(\%)$ & 4,6 & 46,2 & 9,2 & 60,0 & 35,4 & 4,6 & 40,0 & 100 \\
\hline
\end{tabular}

Fonte: Banco de Opiniões dos Eleitores sobre Políticas Públicas (Necip, UFSC). Elaboração nossa.

feito em relação ao plantio destes organismos, enquanto as dúvidas não forem esclarecidas: deveria ser proibido ou não deveria ser proibido?"

${ }^{22} \mathrm{O}$ artigo 5, inciso XLVII, alínea "a” da Constituição Federal diz que "não haverá penas de morte, salvo em caso de guerra declarada, nos termos do art. 84, XIX”. Para efeito de nossa análise, consideramos que os cidadãos, quando perguntados sobre a pena de morte, não estão pensando em casos de guerra.

${ }^{23}$ Conforme pode ser percebido nas tabelas anteriores, além da pena de morte, também classificamos como casos de tipos diferentes os seguintes temas: o aborto em caso de estupro; a criação ou recriação da CPMF e as cotas sociais e raciais para ingresso em universidades públicas. 
Dos 65 casos aqui considerados, 39 foram de congruência (60\%) e 26 de incongruência (40\%) entre a legislação e a opinião da maioria dos cidadãos. A área da saúde foi aquela em que ocorreu mais congruência entre a legislação e a opinião do público (73\%), seguida da área do trabalho (62,5\%). Nas outras duas áreas - segurança pública e educação - a proporção de casos de incongruência (58\% e 57\%, respectivamente) superou a de casos de congruência. É preciso mencionar que podemos estar superestimando os casos de incongruência na área de educação, que são basicamente os relativos às cotas sociais e raciais para ingresso nas universidades, já que optamos por considerar como "sinceras" as opiniões expressas pelos entrevistados, que correspondem a respostas que são socialmente desejáveis.

Dos 39 casos de congruência, 30 (77\%) correspondem à situação em que não houve mudança na legislação ao longo do período, estando essa manutenção da legislação vigente de acordo com a opinião expressa pela maioria dos cidadãos. Nos outros nove casos de congruência, houve mudança na legislação; seis foram classificados como casos de aprovação, por parte do público, de mudanças recentes na legislação (ou seja, feitas no máximo dois anos antes da pesquisa de opinião em pauta), configuran๑ do uma situação em que é mais difícil postular ণิ uma relação de responsividade do Congresso

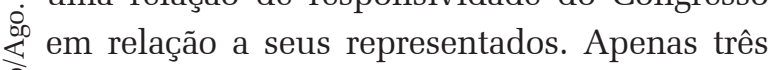

Tabela 7 - Diferencial médio (\% em cada faixa e diferencial médio geral)

\begin{tabular}{|c|c|c|c|c|c|c|c|}
\hline \multirow{2}{*}{$\begin{array}{l}\text { Congruência, } \\
\text { Incongruência }\end{array}$} & \multirow{2}{*}{ Tipos } & \multirow{2}{*}{$(\mathrm{N})^{*}$} & \multirow{2}{*}{$\begin{array}{l}\text { Dif. } \\
\text { Médio } \\
(\%)\end{array}$} & \multicolumn{4}{|c|}{ Faixas de Diferencial (\%) } \\
\hline & & & & 0 a 10 & +10 a 30 & +30 a 50 & +50 \\
\hline \multirow{4}{*}{ Congruência } & 1 & 3 & 55,0 & 9,1 & -- & -- & 8,7 \\
\hline & 2 & 28 & 35,2 & 54,5 & 57,1 & 36,4 & 43,5 \\
\hline & 3 & 6 & 61,4 & -- & -- & 9,1 & 21,7 \\
\hline & Total & 37 & 41,1 & 63,6 & 57,1 & 45,5 & 73,9 \\
\hline \multirow{3}{*}{ Incongruência } & 4 & 19 & 38,0 & 36,4 & 28,6 & 45,5 & 6 \\
\hline & 5 & 3 & 33,5 & -- & 14,3 & 9,1 & -- \\
\hline & Total & 22 & 37,4 & 36,4 & 42,9 & 54,5 & 26,1 \\
\hline \multicolumn{2}{|l|}{$(N)^{*}$} & (59) & 39,3 & (11) & (14) & (11) & (23) \\
\hline
\end{tabular}

Fonte: Banco de Opiniões dos Eleitores sobre Políticas Públicas (Necip, UFSC). Elaboração nossa.

* O número de casos aqui é inferior a 65 porque, em alguns casos, o diferencial médio não foi computado, conforme observações em cada Tabela. casos de congruência se aproximariam mais do caso típico de uma mudança de legislação "em resposta" a uma manifestação majoritária da população a favor dessa mudança (embora, como já foi ressalvado, a simples precedência temporal de uma pesquisa de opinião em relação a uma mudança na legislação não garanta que se trata desse tipo de responsividade).

Dos 26 casos de incongruência, 23 $(88,5 \%)$ correspondem também a uma "inércia legislativa”, ou seja, são casos em que, embora a opinião majoritária fosse a favor de uma mudança na legislação em vigor, essa mudança não ocorreu. Nos outros três casos de incongruência (11,5\% dos 26 casos de incongruência; $4,6 \%$ do total de casos analisados), o Congresso acabou por aprovar uma legislação que ia contra a opinião majoritária dos cidadãos.

Desse modo, a análise revela um viés "conservador", em matéria da legislação: tanto nos casos de congruência quanto nos de incongruência, predominam as situações em que não há mudança da legislação. $82 \%$ dos 65 casos aqui analisados correspondem ao que poderia ser chamado de "inércia legislativa".

A Tabela 7 apresenta dados sobre o "diferencial”, tal como é definido na primeira hipótese (H1), distinguindo-se três faixas de diferencial e apresentando, para cada tipo (de congruência ou incongruência), o diferencial médio.

Analisando-se, inicialmente, o diferencial médio geral para cada tipo de caso, percebe-se que, nos casos enquadrados nos tipos 1 e 3 de congruência, tende a haver uma posição majoritária mais nítida (diferenciais médios de 55\% e 61,4\%, respectivamente) do que nos demais tipos de casos. Quando comparamos o conjunto de casos de congruência com o conjunto dos casos de incongruência, porém, as diferenças são pouco significativas 
(41,1\% e 39,3\%, respectivamente). Isso ocorre porque, no tipo mais frequente de congruência (tipo 2), a diferença média entre opiniões majoritária e minoritária $(35,2 \%)$ é até um pouco menor do que a correspondente no principal tipo de incongruência (tipo 4): 38,0\%.

Quando analisamos por faixas de diferencial, vemos que não há um crescimento linear da porcentagem de casos de congruência à medida que passamos dos casos em que a opinião está mais dividida (0 a 10\% de diferença entre as proporções da população que esposam as opiniões majoritária e minoritária) para os casos em que há uma clara maioria (mais de 50\% de diferencial). Na realidade, há um declínio daquela porcentagem, de $63,6 \%$ na primeira faixa até $45,5 \%$, na faixa de diferencial de $30 \%$ a 50\%. Mas, na faixa de maior diferencial (mais de 50\%), há um salto na porcentagem dos casos de congruência, que correspondem a 74\% dos casos nessa faixa. Assim, nossos dados não corroboram a primeira hipótese, tal como foi formulada. Mas os dados mostraram uma tendência de predomínio de congruência nos casos em que há uma opinião apoiada por uma enorme maioria da população. É possível supor que os representantes avaliem que, nesses casos, o custo eleitoral de aprovar uma legislação contra a opinião dessa "supermaioria” da população seja muito elevado.

Quanto à hipótese 2, que relaciona a congruência com o grau de saliência dos temas, os dados relativos às respostas NS e NR não se mostraram muito úteis para diferenciar os casos: tanto no conjunto dos casos de congruência quanto no conjunto dos casos de incongruência, a média de respostas NS e NR foi de 6,4\%. A análise que toma o número de pesquisas como

Tabela 8 - Casos de congruência e incongruência segundo número de pesquisas - (tomado como indicador da saliência do tema) (\%)

\begin{tabular}{l|c|c|c|c|c}
\hline \multirow{2}{*}{ Casos } & \multicolumn{4}{|c|}{ Quantidade de pesquisas (para cada caso) } & \multirow{2}{*}{ Total (N) } \\
\cline { 2 - 5 } & 1 & 2 a 4 & 5 a 9 & $10 \mathrm{ou}+$ & \\
\hline Congruência & 61,8 & 57,9 & 50,0 & 75 & $(39)$ \\
\hline Incongruência & 38,2 & 42,1 & 50,0 & 25 & $(26)$ \\
\hline Total (N) & $(34)$ & $(19)$ & $(8)$ & $(4)$ & $(65)$ \\
\hline
\end{tabular}

indicador do grau de saliência de um tema também não mostra uma tendência unívoca no sentido de haver um aumento no percentual de congruência à medida que passamos dos temas para os quais temos menos, para os temas para os quais temos mais pesquisas (Tabela 8).

Uma análise qualitativa dos casos que mais apareceram nas pesquisas - relacionados aos temas do aborto, uso de drogas, pena de morte e redução da maioridade penal (todos temas com mais de 10 pesquisas ao longo do período estudado) - deixa clara a mesma conclusão. No que se refere ao tema do aborto, com poucas exceções, a grande maioria corresponde a casos em que há congruência entre a legislação em vigor e a opinião da maioria dos cidadãos. O mesmo vale para o uso de drogas, cuja proibição é apoiada pela grande maioria da população. Já o caso da pena de morte revela maior variação da opinião da população ao longo do tempo, passando de um período inicial (1991-2001) em que a opinião majoritária era a favor da pena capital (em desacordo com legislação), para um período de alternância das opiniões majoritárias (20012008). Até chegar num período (2008-2017) de predomínio de uma opinião majoritariamente contra (em sintonia com a legislação).

Por fim, o caso mais claro de desconsideração, pelo Congresso, da opinião do eleitorado brasileiro é o da proposta de redução da maioridade penal: 21 pesquisas entre 2002 e 2015 revelam uma ampla, generalizada e contínua maioria da população a favor da redução da maioridade penal, sem que o Congresso tenha aprovado uma mudança nessa legislação. ${ }^{24}$ Resumindo: em dois desses temas mais pesquisados, houve congruência; em um, há uma incongruência da legislação frente a uma sólida e contínua maioria e, num quarto tema, tem havido alternância ao longo do tempo entre situações de congruência e incongruência entre a legislação e a opinião ma-

${ }^{24}$ Um quinto tema com uma frequência de aparições nas pesquisas um pouco menor do que os desses quatro acima foi o do uso das Forças Armadas no combate à violência. Como vimos, embora tenhamos classificado o caso como de incongruência, trata-se de um caso de interpretação duvidosa. De qualquer forma, sua inclusão não mudaria substancialmente as conclusões a seguir. 
joritária dos cidadãos. Assim, tanto com base nas análises que tomam indicadores quantitativos de saliência quanto com base nessa análise qualitativa dos temas mais frequentes nas pesquisas, a hipótese 2 (H2) não foi corroborada: não há associação entre saliência dos temas e o grau de congruência (entre legislação e opinião da maioria da população).

\section{CONSIDERAÇÕES FINAIS}

Quanto à evolução da opinião dos cidadãos brasileiros a respeito dos temas estudados, cabe destacar aqui apenas as tendências mais gerais relativas aos itens para os quais há um conjunto mais significativo de dados. Em relação à área de educação, a maioria dos brasileiros tem se mostrado contra a cobrança de mensalidades nas universidades públicas. A maioria também mostrou apoio às cotas sociais e raciais para ingresso nas universidades (públicas e privadas), tanto em momentos anteriores quanto logo após a aprovação da legislação que institui essas cotas. Como já foi mencionado, porém, as relações entre as respostas de entrevistados e suas "opiniões sinceras" a respeito de questões socialmente delicadas, como a das cotas raciais, podem ser F complexas, dificultando afirmações mais sóliণิ das sobre as reais tendências da opinião dos cidadãos. No que tange aos temas trabalhistas, apenas em relação a dois itens dispomos de várias pesquisas ao longo do tempo. A maioria dos cidadãos tem se manifestado continuamente contra a proibição do direito de greve. : Interessante é o posicionamento em relação à "livre negociação entre patrões e empregados": em cinco pesquisas realizadas durante a década de 1990, a maioria se manifestou favorável (mesmo quando o enunciado da pergunta mencionava explicitamente a eventual perda ou suspensão de direitos). Já em 2017, alguns meses antes da efetiva aprovação da chamada Reforma Trabalhista, a maioria da população se manifestou contra. Talvez a iminência da aprovação da reforma e um debate maior sobre ela tenham influenciado essa mudança.

Quanto à área de saúde, o tema para o qual dispomos de mais dados é o aborto. Os brasileiros e as brasileiras têm se mostrado majoritariamente favoráveis a que as mulheres possam decidir livremente sobre o aborto nos casos já previstos na lei (estupro e risco de vida à mulher), mas também nos casos em que a gestante tem AIDS ou quando o feto apresenta problema grave. Nos demais casos (quando a mulher desejar, quando tiver menos do que 18 anos, quando não for casada, quando o anticoncepcional falhar, quando o casal não quiser mais filhos, ou quando a família não tiver condições socioeconômicas), a maioria dos cidadãos e cidadãs é contra a legalização do aborto. Além disso, a maioria da população se manifestou, em várias ocasiões, contra a criação e, depois, a reedição, da CPMF. Por fim, na área de segurança pública, como foi visto, ocorreu uma mudança na posição majoritária dos brasileiros em relação à pena de morte: de um período em que a maioria era a favor, passamos para outro em que houve sucessivas mudanças na opinião majoritária, chegando-se a um posicionamento majoritariamente contra, nos últimos anos. Os brasileiros também se mostram majoritariamente contra a legalização das drogas e a favor do uso das Forças Armadas na segurança pública, da prisão perpétua e da redução da maioridade penal.

Embora, evidentemente, não seja possível generalizar, talvez se possa dizer que a opinião majoritária dos cidadãos brasileiros tem se mostrado mais "progressista” em relação às políticas de educação e de trabalho e mais "conservadora" em matéria de saúde (na realidade, em relação ao tema do aborto, que envolve uma forte dimensão moral e mesmo religiosa) e, principalmente, em relação à área de segurança pública. ${ }^{\mathrm{a} a s, ~ m e s m o ~ n e s s a ~ u ́ l t i m a, ~}$ como vimos, em relação ao tema da pena de morte, a tendência mais geral foi da passagem de um período em que a maioria era favorável (1991-2001) para um em que a maioria era contra a pena de morte (2008-2015). Se aceitarmos 
a avaliação (influente) de que a parcela da população favorável à pena de morte é constituída principalmente por cidadãos "conservadores", para quem a repressão é a forma por excelência de combater a violência na sociedade, a tendência indicada acima estaria em contradição com certa percepção (também influente) de que estaríamos passando por um aumento do conservadorismo na sociedade brasileira.

Quanto à análise de congruência entre as políticas aprovadas pelo Congresso e a opinião majoritária do eleitorado, antes de sistematizar os principais achados de nosso trabalho, cabe indicar algumas das principais limitações da análise. Em primeiro lugar, há uma questão mais geral desse tipo de estudo: mesmo que haja congruência entre opinião majoritária e legislação, não há segurança em afirmar que haja qualquer relação de causalidade envolvida. Pode-se, no máximo, sugerir isso como uma possibilidade. Em segundo lugar, a escassez de dados dificulta verificar a evolução da opinião em relação à maioria dos casos (para os quais há apenas uma ou poucas pesquisas), o que aumenta a dificuldade de sugerir possíveis relações de causalidade: se há, por exemplo, apenas uma pesquisa (ou poucas) em relação a um tema, não é possível afirmar que seus resultados configuram uma tendência, especialmente se as opiniões estiverem razoavelmente divididas na população.

De toda forma, a partir dos dados disponíveis, comparando-se a trajetória da opinião pública em relação a uma variedade de temas com os momentos de alteração legislativa ou com a legislação vigente por um determinado período, foi possível observar alguns padrões entre os temas.

A partir de uma tipologia inicial, sujeita a aprimoramentos, verificamos que ocorre congruência entre a legislação aprovada ou em vigor no período estudado e a opinião da maioria da população na maioria dos "casos" analisados (61\%). A maior parte desses casos corresponde à situação em que não houve mudança na legislação ao longo do período, estando essa manutenção da legislação vigente de acordo com a opinião expressa pela maioria dos cidadãos. São poucos os casos que poderiam corresponder a uma situação mais claramente de responsividade (ou ativa) dos representantes, no sentido de aprovarem mudanças na legislação (dentro de um prazo razoável) para adequá-la à opinião majoritária da população (captada através de pesquisas de opinião). Da mesma forma, entre os casos de incongruência, predominam aqueles em que, embora a opinião majoritária fosse a favor de uma mudança na legislação em vigor, essa mudança não ocorreu.

A análise revela, portanto, um viés "conservador" em matéria da legislação: tanto nos casos de congruência quanto nos de incongruência, predominam situações em que não há mudança da legislação. 82\% dos 65 casos aqui analisados correspondem ao que poderia ser chamado de inércia legislativa. Mesmo supondo que os parlamentares tenham conhecimento das opiniões expressas pela população, essa inércia, porém, provavelmente, teria significados diferentes nos casos de congruência e de incongruência. Esse predomínio poderia indicar, de um lado, uma tendência de nossos congressistas a não alterar uma legislação que percebam como tendo apoio da maioria da população; de outro, uma dificuldade de coordenação de uma maioria parlamentar para fazer mudanças legislativas que possam desagradar parcelas do eleitorado (ou eleitores influentes, como os financiadores de campanha), mesmo sabendo que há uma maioria da população a favor das mudanças.

No teste das duas hipóteses propostas, se tomarmos a primeira (H1), tal como foi formulada - "quanto maior a diferença entre a porcentagem da população que sustenta a opinião majoritária e a porcentagem que adere à opinião minoritária em relação a um tema, maior a chance de haver congruência" -, não é possível dizer que os dados a corroboram, já que não há uma tendência de crescimento dos casos de congruência à medida que passamos 
dos casos em que há mais equilíbrio na opinião dos cidadãos para aqueles casos em que há uma maioria clara. Mas os dados mostraram uma tendência de predomínio de congruência nos casos em que há uma opinião apoiada por uma enorme maioria da população. É possível supor que os representantes avaliem que, nesses casos, o custo eleitoral de se colocar contra a opinião dessa "supermaioria" da população seja muito elevado. A não aprovação da redução da maioridade penal - que tem tido apoio constante de uma grande maioria da população -, porém, é um caso importante contrário a essa suposição. Esse é um caso muito interessante também porque revela como a discussão sobre a relação entre responsividade (dos representantes às preferências dos representados) e "boa" representação envolve um grau elevado de normatividade: é possível dizer que certo ponto de vista "progressista" que questiona a "falta de representatividade" de nossos parlamentares em muitos aspectos, aqui muito provavelmente criticaria fortemente esses mesmos parlamentares se fossem responsivos ao eleitorado, aprovando a redução da maioridade penal.

Quanto à segunda hipótese, nossa análise não a corrobora. Os dados não permitem afirmar que, em casos relativos a temas mais salientes para o público, haveria uma tendência maior ๑) de os representantes legislarem em consonância com a opinião da maioria desse público.

Finalizando, há uma grande escassez, em nossa literatura, em relação a esse tipo de estudos, e esperamos que esta possa ser uma contribuição que estimule a produção empírica sobre representação política no Brasil sob $\therefore$ a perspectiva da congruência política entre a ; ação dos representantes e as preferências dos ले representados. Esperamos também que o debate deste artigo, especialmente das questões metodológicas aí envolvidas, possa contribuir para o aprimoramento de futuras análises.

Recebido para publicação em 16 de março de 2018 Aceito em 01 de julho de 2019

\section{REFERÊNCIAS}

AMES, B.; PEREIRA, C.; RENNÓ, Lo. Famintos por pork. Uma análise da demanda e da oferta por políticas localistas e suas implicações para a representação política. In: Power, T.; Zucco JUNIOR, C. (Org.) O Congresso por ele mesmo. Autopercepções da classe política brasileira. Belo Horizonte: Ed. UFMG, 2011.

ANDRADE, J. M de. O contrato de trabalho e sua alteração. Ed. LTR, 1986. p. 147.

BOAS, T.; SMITH, A E. Looks Like Me, Thinks Like Me? Descriptive Representation and Opinion Congruence in Brazil. Ago. 2017. Disponível em http://people.bu.edu/ tboas/looks_like_me.pdf. Acesso em: 15.02.2018.

BUDGE, I. et al. Organizing democratic choice. Party representation over time. Oxford: Oxford University Press, 2012.

CARREIRÃO, Y.; MELO, D. J. C. Representação política na Assembleia Nacional Constituinte (1987-88): congruência entre preferências dos cidadãos e políticas aprovadas na Constituição. Teoria \& Pesquisa, São Paulo, v. 23, p. 107-149, 2014.

CARREIRÃO, Y. Representacão política como congruência entre as preferências dos cidadãos e as políticas públicas: uma revisão da literatura internacional. Opinião Pública, Campinas, v. 21, p. 393-430, 2015.

DALTON, R. Citizen politics. Public opinion and political parties in advanced industrial democracies. Washington: CQ Press, 2008.

DALTON, R.; FARRELL, D.; McALLISTER, I. Political parties and democratic linkage. Oxford: Oxford University Press, 2011.

GOLDER, M.; STRAMSKI, J. ideological congruence and electoral institutions. American Journal of Political Science, [s.1], v. 54, n. 1, p. 90-106, 2010.

MANIN, B.; PRZEWORSKI, A.; STOKES, S. Introduction. In: PRZEWORSKI, A.; STOKES, S.; MANIN, B. Democracy, accountability, and representation. Cambridge: Cambridge University Press, 1999.

MILLER,W.; STOKES, D. Constituency influence in Congress. American Political Science Review, [sl], v.57, p. 45-56, 1963.

MONROE, A. Consistency between constituency preferences and national policy decisions. American Politics Quarterly, United States, v. 12, p. 3-19,1979.

MONROE, A. Public opinion and public policy, 1980-1993. The Public Opinion Quarterly, [s.l], v. 62, n. 1, p. 6-28, 1998.

PAGE, B.; SHAPIRO, R. Effects of public opinion on policy. American Political Science Review, [s.l], v. 77, n. 1, p. 175-190, 1983.

PEDERIVA, J.; RENNÓ, L. Responsividade democrática no Brasil de Lula e na Argentina dos Kirchner. Jundiaí: Paco Editorial, 2015.

PITKIN, H. The concept of representation. Berkeley: University of California Press, 1967.

ROHRSCHNEIDER, R.; WHITEFIELD, S. The strain of representation: How parties represent diverse voters in Western and Eastern Europe. Oxford: Oxford University Press, 2012.

SOROKA, S.; WLEZIEN, C. Degrees of democracy. Politics, public opinion, and policy. New York: Cambridge University Press, 2010.

TURGEON, M.; CHAVES, B.; WIVES, W. Políticas de ação afirmativa e o experimento de listas: o caso das cotas raciais na universidade brasileira. Opin. Pública, Campinas, v. 20, n. 3, p. 363-376, 2014.

WEISSBERG, R. Collective vs. dyadic representation in Congress. American Political Science Review, [s.l], n. 72, p. 535-547, 1978. 


\section{CONGRUENCE BETWEEN SOCIAL AND PUBLIC SECURITY POLICIES AND CITIZENS' OPINION IN BRAZIL}

\author{
Yan de Souza Carreirão \\ Peterson Roberto da Silva \\ Maria Teresa De Bastiani
}

\section{CONGRUENCE ENTRE LES POLITIQUES SOCIALES ET DE SECURITE PUBLIQUE ET LES OPINIONS DES CITOYENS AU BRESIL}

\author{
Yan de Souza Carreirão \\ Peterson Roberto da Silva \\ Maria Teresa De Bastiani
}

This work is located within a field of empirical studies on political representation, according to the analytical perspective of "political congruence", an important field in the international literature, though little developed in Brazil. It analyzes, on the one hand, the evolution of opinions among Brazilian citizens on social (health, education and labor policies) and public security issues, and on the other, to what extent there is congruence between these opinions and the legislation in effect about them. Although it is not possible to make generalizations, the conclusions of the article show that the majority of the Brazilian citizens' opinions have been more "progressive" when it comes to education and labor policies, but more "conservative" regarding abortion and, mainly, public security policies. Concerning legislation, the analysis reveals a high degree of "legislative inertia": in both cases of congruence and incongruence, the permanence of legislation predominates.

Keywords: Political behavior. Political representation. Public opinion. Political congruence. Public policies.
Ce travail s'insère dans le champs des études empiriques concernant la représentation politique dans une perspective d'analyse de la "congruence politique”, um domaine d'étude important de la littérature scientifique internationale, mais encore peu développé au Brésil. Il analyse, d'un côté, l'évolution de les opinions des citoyens brésiliens sur des sujets liés au domaine social (santé, éducation, travail) ainsi qu’à celui de la sécurité publique, et d'un autre, dans quelle mesure, il existe des congruences entre ces opinions et la législation em vigueur sur ces thèmes. Bien qu'il ne soit pas possible de généraliser, les conclusions du travail montrent que l'opinion majoritaire des citoyens brésiliens a été plus "progressiste" en ce qui concerne les politiques d'éducation et du travail et plus "conservatrice" sur celles liées à l'avortement et, principalement, aux thèmes relevant de la sécurité publique. En ce qui concerne la législation, l'analyse révèle un degré élevé d'inertie législative: la non-législation prédomine aussi bien dans les cas de congruence que d'incongruence.

Mots-Clés: Comportement public. Représentation politique. Opinion publique. Congruence politique. Politiques publiques.

\footnotetext{
Yan de Souza Carreirão - Doutor em Ciência Política pela Universidade de São Paulo. Professor Titular da Universidade Federal de Santa Catarina. Foi coordenador do Programa de Pós-Graduação em Sociologia Política da UFSC (2014-15). Membro da Diretoria da ANPOCS (2006-08) e Coordenador da Área Temática "Eleições e representação política" da Associação Brasileira de Ciência Política (2012-17). Coordena o Núcleo de Estudos em Comportamento e Instituições Políticas (UFSC). Publicações recentes: $O$ debate metodológico nos estudos de congruência política: uma revisão da literatura internacional. Revista de Sociologia e Política, v. 27, p. 1-28, 2019; Determinantes individuais e de contexto da simpatia partidária na América Latina. Revista Brasileira de Ciências Sociais (online), v. 33, p. 1-25, 2018; Sentimentos partidários e antipetismo: condicionantes e covariantes. Opiniao Publica, v. 22, p. 603-637, 2016.

Peterson Silva - Doutorando em Sociologia Política pela Universidade Federal de Santa Catarina. Bolsista CNPq. Tem experiência na área de Ciência Política, com ênfase em Teoria Política Contemporânea, atuando principalmente em temas como liberdade, legitimidade, representação e anarquismo. Também tem interesse por ensino de ciências sociais e interfaces entre teoria política e ficção/literatura. Traduziu para o português brasileiro junto a Jean Costa "Contesting Nietzsche", de Christa Davis Acampora (no prelo). Recentemente publicou "O desfecho de Caleb Williams: A influência da narrativa sobre a política de William Godwin” na Revista de Ciências do Estado (2017)

Maria Teresa De Bastiani - Bacharel em Ciências Sociais pela Universidade Federal de Santa Catarina. Participa do Núcleo de Estudos em Comportamento e Instituições Políticas (NECIP), desenvolvendo pesquisas na área de representação política, congruência política e opinião pública. Atualmente, graduanda em Arquivologia pela Universidade Federal de Santa Catarina.
} 
